\title{
New poly(ester urea) derived from L-leucine: Electrospun scaffolds loaded with antibacterial drugs and enzymes
}

\author{
Angélica Díaz a , Luis J. del Valle a , David Tugushi ${ }^{\text {, }}$, Ramaz Katsarava ${ }^{\text {b }}$, Jordi Puiggalí ${ }^{a, *}$ \\ a Departament d'Enginyeria Química, Universitat Politècnica de Catalunya, Av. Diagonal 647, Barcelona E-08028, Spain \\ ${ }^{\mathrm{b}}$ Institute of Chemistry and Molecular Engineering, Agricultural University of Georgia, $13 \mathrm{~km}$. David Aghmashenebeli Alley, Tblisi 0131, Georgia
}

\section{A R T I C L E I N F O}

\section{Article history:}

Received 28 June 2014

Received in revised form 18 September 2014

Accepted 21 October 2014

Available online 23 October 2014

\section{Keywords:}

Poly(ester urea)

L-Leucine

Electrospinning

Scaffold

Enzymatic degradation

Biocompatibility

Biguanide

Drug release

\begin{abstract}
A B S T R A C T
Electrospun scaffolds from an amino acid containing poly(ester urea) (PEU) were developed as promising materials in the biomedical field and specifically in tissue engineering applications. The selected poly(ester urea) was obtained with a high yield and molecular weight by reaction of phosgene with a bis $(\alpha$-aminoacyl $)$ - $\alpha, \omega$-dioldiester monomer. The polymer having L-leucine, 1,6-hexanediol and carbonic acid units had a semicrystalline character and relatively high glass transition and melting temperatures. Furthermore it was highly soluble in most organic solvents, an interesting feature that facilitated the electrospinning process and the effective incorporation of drugs with bactericidal activity (e.g. biguanide derivatives such as clorhexidine and polyhexamethylenebiguanide) and enzymes (e.g. $\alpha$-chymotrypsin) that accelerated the degradation process. Continuous micro/nanofibers were obtained under a wide range of processing conditions, being diameters of electrospun fibers dependent on the drug and solvent used.

Poly(ester urea) samples were degradable in media containing lipases and proteinases but the degradation rate was highly dependent on the surface area, being specifically greater for scaffolds with respect to films. The high hydrophobicity of new scaffolds had repercussions on enzymatic degradability since different weight loss rates were found depending on how samples were exposed to the medium (e.g. forced or non-forced immersion). New scaffolds were biocompatible, as demonstrated by adhesion and proliferation assays performed with fibroblast and epithelial cells.
\end{abstract}

(c) 2014 Elsevier B.V. All rights reserved.

\section{Introduction}

Poly(ester urea)s (PEUs) have been proposed as a new class of $\alpha$ amino acid-based polymers with bioabsorbable properties. These polymers can be easily prepared from bis( $\alpha$-amino acid)-alkylene diester monomers, which can undergo either nonspecific (chemical) or specific (enzymatic) hydrolysis due to the presence of two ester linkages per elemental unit in the molecule. The first syntheses were reported in the late 1970s by Huang et al. [1] and yielded low molecular weight powdery samples $\left(M_{n}\right.$ close to $2000 \mathrm{~g} / \mathrm{mol}$ ). Later, Yoneyama et al. synthesized high molecular weight PEUs by condensing the above diester-diamine monomers with non-physiological diisocyanates [2]. In order to avoid the use of diisocyanates, other syntheses based on polycondesation processes through active carbonates (e.g. di-pnitrophenyl carbonate) were investigated [3]. However, presumably intramolecular cyclization with hydantoin formation, which represent a chain scission process, led to low molecular weight polymers.

Problems were solved when an acid chloride of carbonic acid (phosgene, diphosgene, triphosgene) was entered into the polycondensation

\footnotetext{
* Corresponding author.

E-mail address: Jordi.Puiggali@upc.edu (J. Puiggalí).
}

reaction with a di- $p$-toluenesulfonic acid salt of a bis( $\alpha$-amino acid)alkylene diester (Fig. 1a) [4]. In the interfacial polycondensation reaction, the nucleophilic amino group was readily revealed by addition of an inorganic base, such as $\mathrm{NaOH}, \mathrm{NaHCO}_{3}$ and $\mathrm{Na}_{2} \mathrm{CO}_{3}$. This method provides high-yield, high-molecular weight PEUs potentially useful for biomedical applications because of their advantageous mechanical, chemical and biodegradation properties over well-known, chemically similar poly(ester amide)s also derived from $\alpha$-amino acids [5]. For example, the PEU derived from carbonic acid, L-leucine, and 1,6hexanediol (named 1L6, as indicated in Fig. 1a) has tensile strength at yield, elongation at break and Young's modulus of $21 \mathrm{MPa}, 114 \%$ and $622 \mathrm{MPa}$, respectively [4]. Its melting temperature is $114{ }^{\circ} \mathrm{C}$ and its glass transition temperature is $47{ }^{\circ} \mathrm{C}$. New PEUs were proposed to be useful as implantable surgical devices such as vascular stents and hard tissue replacement implants, and also for delivery of a variety of pharmaceutical and biologically active agents to humans and other mammals.

Micro/nanofiber nonwoven scaffolds produced by electrospinning have shown great potential for tissue engineering applications because of their typically high surface area and porosity. Electrospinning is a well-known electrostatic technique that uses a high voltage field to charge the surface of a polymer solution droplet at the end of a capillary 
$\mathrm{TsO}^{-} \mathrm{NH}_{3} \mathrm{CH}\left(\mathrm{CH}_{2} \mathrm{CH}\left(\mathrm{CH}_{3}\right)_{2}\right) \mathrm{CO}-\mathrm{O}\left(\mathrm{CH}_{2}\right)_{6} \mathrm{O}-\mathrm{COCH}\left(\mathrm{CH}_{2} \mathrm{CH}\left(\mathrm{CH}_{3}\right)_{2}\right) \mathrm{NH}_{3}{ }^{+-} \mathrm{OTs}$

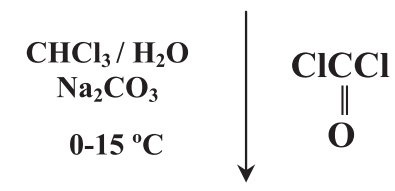 \\ - [-CO-NHCH$\left.\left(\mathrm{CH}_{2} \mathrm{CH}\left(\mathrm{CH}_{3}\right)_{2}\right) \mathrm{CO}-\mathrm{O}\left(\mathrm{CH}_{2}\right)_{6} \mathrm{O}-\mathrm{COCH}\left(\mathrm{CH}_{2} \mathrm{CH}\left(\mathrm{CH}_{3}\right)_{2}\right) \mathrm{NH}-\right]_{n}-$
}

1L6: PEU derived from carbonic acid (1), L-Leucine (L) and 1,6-hexanediol (6)

b)

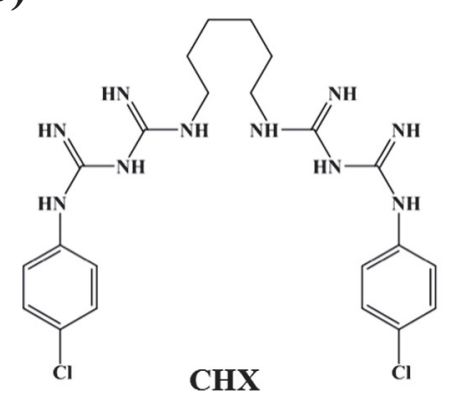

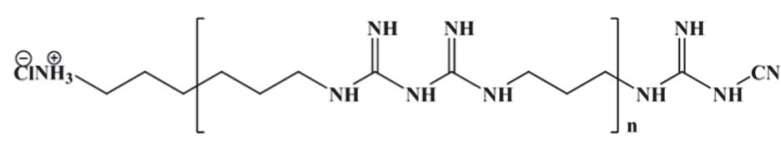

PHMB

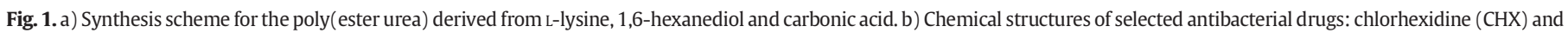
polyhexamethylenebiguanide hydrochloride (PHMB).

tube and induce the ejection of a liquid jet towards a grounded target (collector) [6-9]. Morphology of fibers obtained in the collector depends on the solution properties (e.g. viscosity, dielectric constant, volatility and concentration) and operational parameters (e.g. strength of the applied electric field, deposition distance and flow rate), which should be conveniently addressed $[10,11]$.

The unique properties of electrospun fibers have triggered a wide range of other potential applications [12], including composites [13, 14], sensors [15], protective clothing [16], filtration membranes [17-20], magneto-responsive fibers and superhydrophobic membranes [21]. In addition, the electrospinning process provides a simple way to encapsulate drugs within a micro/nanofiber matrix that can lead to a controlled and sustained release. Several natural and synthetic biodegradable polymers have been successfully electrospun (e.g. polyglycolide [22], polylactide [22,23], polycaprolactone [24], collagen $[25,26]$ and chitosan [26,27]).

The main goal of the present work is to explore the possibilities of PEUs, and specifically of the 1L6 sample, for preparing electrospun scaffolds. Furthermore, loading with anti-bactericidal agents having biguanide groups is explored, as well as the possibility of incorporating degrading agents such as a proteolytic enzyme like $\alpha$-chymotrypsin. To the best of our knowledge, this is the first time that a poly(ester urea) has been assayed as an electrospinnable polymer, which is in itself an interesting topic because it adds to the range of materials useful for tissue engineering applications. Furthermore, development of antibacterial nanofibers through electrospinning is nowadays a relevant topic for wound dressing applications as has recently been reviewed by Gao et al. [28]. Different systems have been considered taking into account the substrate polymer (e.g., polylactide and polycaprolactone), the antibacterial agent (e.g., antibiotic, bactericide, silver and metal oxide nanoparticles and chitosan) and the applied procedure (incorporation of the agent in the electrospinning solution, coaxial electrospinning, previous encapsulation of the antibacterial agent, conversion of a precursor to its active form by a post-treatment and attachment of the active agent onto the fiber surface). Specific systems based on the use of bactericide agents are summarized in Table 1 [28], which also reveals the relevance of the use of biguanide derivatives.

Biguanide (Fig. 1b), commonly known as chlorhexidine $\left(1,1^{\prime}\right.$ hexamethylene-bis-5-(4-chlorophenyl) biguanide, CHX), is a widely employed antimicrobial agent [42]. Specifically, CHX is an important antiseptic, disinfectant, pharmaceutical and cosmetic preservative and antiplaque agent. Its high activity against microorganisms is provided by the presence of secondary amines that can be protonated, and therefore positively charged under normal pH conditions [43]. Immobilization of antimicrobial agents may reduce patient exposure to active agents and potentially increase the duration of antimicrobial efficacy $[44,45]$. One way to achieve immobilization is by loading micro/nanofibers of electrospun scaffolds with the desired drug.

Other chemical compounds bearing biguanide groups have been developed $[46,47]$. For example, polyhexamethylenebiguanide hydrochloride (PHMB) is a cationic oligomer having an average of 7-11 biguanide groups spaced by flexible hexamethylene segments (Fig. 1b). PHMB has 
Table 1

Electrospun scaffolds loaded with bactericide agents. ${ }^{\text {a }}$

\begin{tabular}{|c|c|c|c|c|}
\hline Electrospun polymer & Solvent & Concentration & Antibacterial agent & Reference \\
\hline PCL/PLA & $\mathrm{CF} /$ acetone $3: 1 \mathrm{v} / \mathrm{v}$ & $10 \% w / v$ & Triclosan & [29] \\
\hline PLA & CF/DMF 9:1 v/v & $8 \% w / v$ & Triclosan & {$[30]$} \\
\hline $\mathrm{CA}$ & DMF & 3 wt.\% & Chlorhexidine & [31] \\
\hline PAN & DMSO & 15 wt.\% & QACs & [32] \\
\hline $\mathrm{CA} / \mathrm{PEU}$ & DMF/THF 50:50 v/v & 20/10 wt.\% & PHMB & [33] \\
\hline PAN & DMF & $10 \% w / v$ & РHMB & [34] \\
\hline PAN & DMF & 10 wt.\% & $\mathrm{N}$-halamine & [35] \\
\hline PEO/Chitosan & $\mathrm{H}_{2} \mathrm{O} /$ Acetic acid & $3-4$ wt.\% & K5N8Q & [36] \\
\hline PDLLA, PEO & DMF & $20-24$ wt.\% & Antibacterial peptides & [37] \\
\hline PADAS & HFIP & 10 wt.\% & Chlorhexidine & [38] \\
\hline PLA/PCL & CF-acetone $2: 1 \mathrm{v} / \mathrm{v}$ & $10-2.5$ wt.\% & Triclosan & [39] \\
\hline PLA/PEG & DCM/DMF 70:30 v/v & 7-35 wt.\% & Triclosan & {$[40]$} \\
\hline PHB/PEO & $\mathrm{DMF} / \mathrm{CF} 80: 20 \mathrm{v} / \mathrm{v}$ & $10 \% \mathrm{w} / \mathrm{w}$ & Chlorhexidine & [41] \\
\hline
\end{tabular}

a PCL (polycaprolactone), PLA (polylactide), PDLLA (poly(D,L-lactide)), PEG (poly(ethylene glycol)), CA (cellulose acetate), PAN (polyacrylonitrile), PEU (poly (ester urea)),

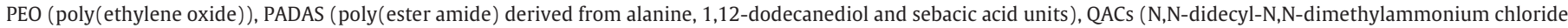

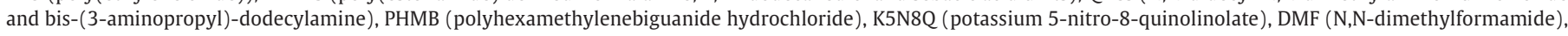
DMSO (dimethyl sulfoxide), THF (tetrahydrifuran), HFIP (hexafluoroisopropanol), PHB (poly(hydroxybutyrate)), CF (Chloroform), DCM (dichloromethane).

chemical stability, low toxicity, high effectiveness against microorganisms and reasonable cost [48-50]. Gilbert et al. demonstrated that activity increased with the number of biguanide groups and that maximum biocidal efficiency was obtained when the hexamethylene group was employed as spacer [51].

\section{Experimental section}

\subsection{Materials}

The poly(ester urea) 1L6 was synthesized with a 91-93\% yield, as shown in the scheme in Fig. 1, following the procedure previously reported by Gomurashvili et al. [4].

All solvents, clorhexidine (CHX $\geq 98 \%$ (HPLC)), 3-(4,5-dimethylthiazol-2-yl)-2,5-diphenyl-2H-tetrazolium bromide (MTT), enzymes (lipase, proteinase $\mathrm{K}$ and $\alpha$-chymotrypsin) and cell culture labware were purchased from Sigma-Aldrich (Spain). Cosmocil® (polyhexamethylenebiguanide hydrochloride, PHMB) (Batch No. 10GR140505) was purchased from Arch UK Biocides (20\% aqueous solution), then lyophilized and provided by B. Braun Surgical, S.A. The microbial culture was prepared with reagents and labware from Scharlab (Spain).

Escherichia coli CECT 101 and Micrococcus luteus CECT 245 bacterial strains were obtained from Spanish Collection of Type Culture (Valencia, Spain). African green monkey kidney fibroblast (COS-7) and epithelial (Vero) cells were purchased from ATCC (USA).

\subsection{Molecular weight characterization of the poly(ester urea) 1 L6}

Weight and number average molecular weights determined by GPC were 74,100 and 51,100 g/mol, respectively. The GPC (Waters Associates, Inc., Milford, United States) was equipped with a high-pressure liquid chromatography pump (Waters 1525 binary HPLC), styragel columns (HR4, HR3 and HR0.5) $(7.8 \mathrm{~mm} \times 300 \mathrm{~mm}$ ) and a refractive index detector (Waters 2414). The polymer was dissolved and eluted in a solution of $\operatorname{LiBr}(0.1 \mathrm{M})$ in dimethylformamide at a flow rate of $1.0 \mathrm{~mL} / \mathrm{min}$ (injected volume $100 \mu \mathrm{L}$, sample concentration $2.0 \mathrm{mg} / \mathrm{mL}$ ). The columns were calibrated with polyethylene glycol standards.

\subsection{Electrospinning}

Electrospun fibers were collected on a target placed at different distances $(10-25 \mathrm{~cm})$ from the needle tip (inside diameter of $0.84 \mathrm{~mm}$ ). The voltage was varied between 10 and $30 \mathrm{kV}$ and applied to the target using a high-voltage supply (Gamma High Voltage Research, ES30-5W). Polymer solutions were delivered via a KDS100 infusion syringe pump (KD Scientific, USA) to control the mass-flow rate (from 0.5 to $10 \mathrm{~mL} / \mathrm{h}$ ). All electrospinning experiments were carried out at room temperature. Unloaded and $\alpha$-chymotrypsin, CHX and PHMB loaded electrospun fibers were prepared using optimized parameters (i.e. needle tip-collector distance, voltage and flow rate) and solvent conditions (i.e. solvent ratio, and polymer and drug concentration). Amounts of CHX, PHMB and $\alpha$-chymotrypsin in the electrospinning solution were selected to render 1L6 scaffolds loaded with 2.8, 0.85 and $10 \mathrm{wt} . \%$ of the respective compounds.

\subsection{Morphology and properties of electrospun scaffolds}

Optical microscopy studies were performed with a Zeiss Axioskop 40 microscope. Micrographs were taken with a Zeiss AxiosCam MRC5 digital camera.

Detailed inspection of texture and morphology of electrospun samples was conducted by scanning electron microscopy using a Focus Ion Beam Zeiss Neon 40 instrument (Carl Zeiss, Germany). Carbon coating was accomplished using a Mitec K950 Sputter Coater fitted with a film thickness monitor $k 150 \times$. Samples were visualized at an accelerating voltage of $5 \mathrm{kV}$. The diameter of electrospun fibers was measured with the SmartTiff software from Carl Zeiss SMT Ltd.

Contact angles (CA) were measured at room temperature with sessile drops using an OCA-15 plus Contact Angle Microscope (Dataphysics, USA) and SCA20 software. Values of the right and left sides of distilled water drops were measured $10 \mathrm{~s}$ after the drop $(5 \mathrm{~mL})$ was deposited on the sample surface. All CA data were an average of six measurements on different surface locations.

\subsection{Degradation studies}

Degradation study samples were cut from regular films of $1 \times 1 \mathrm{~cm}^{2}$ and $200 \mu \mathrm{m}$ in thickness prepared by melt pressing $300 \mathrm{mg}$ of the appropriate polymer at a temperature of $10{ }^{\circ} \mathrm{C}$ above the melting peak temperature or from the mat with an approximate thickness of $60 \mu \mathrm{m}$ recovered from the electrospinning process.

Enzymatic degradation was conducted at $37{ }^{\circ} \mathrm{C}$ using Rhizopus oryzae lipase (56-60 units/mg), proteinase $\mathrm{K}$ ( $1 \mathrm{unit} / \mathrm{mL}$ ) and $\alpha$ chymotrypsin (40 units/mg). The enzymatic medium, $1 \mathrm{~mL}$, consisted of a pH 7.4 sodium phosphate buffer containing sodium azide (0.03 wt\%) and 1, 0.1 and $1 \mathrm{mg}$ of lipase, proteinase $\mathrm{K}$, and $\alpha$-chymotrypsin, respectively. All enzymatic solutions were renewed every $48 \mathrm{~h}$ because of enzymatic activity loss. After immersion, samples were rinsed with water, dried to constant weight under vacuum and stored over $\mathrm{P}_{4} \mathrm{O}_{10}$ before analysis. Weight retention was then evaluated. Degradation studies were performed in quadruplicate, with given data corresponding to the average values. 
Morphology of degraded films was inspected by scanning electron microscopy using a Focus Ion Beam Zeiss Neon 40 instrument (Carl Zeiss, Germany). Carbon coating was performed using a Mitec K950 Sputter Coater fitted with a film thickness monitor $k 150 \times$. Samples were visualized at an accelerating voltage of $5 \mathrm{kV}$.

\subsection{Release experiments}

Controlled release measurements were made with square pieces (weighing approximately $200 \mathrm{mg}$ ) of the electrospun scaffolds. These pieces were weighed and incubated at $37{ }^{\circ} \mathrm{C}$ in an orbital shaker at $200 \mathrm{rpm}$ in tubes of $50 \mathrm{~mL}$ for 1 week. PBS buffer (hydrophilic medium) and, alternatively, its mixture with ethanol (i.e. 3:7 v/v ratio) as a more hydrophobic component, were used as release media. Drug concentration was evaluated by UV spectroscopy using a Shimadzu 3600 spectrometer. Calibration curves were obtained by plotting absorbance measured at 252 and $234 \mathrm{~nm}$ versus CHX and PHMB concentration, respectively, in the hydrophilic medium, whereas 261 (for CHX) and $236 \mathrm{~nm}$ (for PHMB) were considered when ethanol was added. Samples were withdrawn from the release medium at predetermined time intervals. The volume was kept constant by addition of fresh medium. All drug release tests were carried out using three replicates and the results were averaged.

Absorbance measurements ( $282 \mathrm{~nm}$ ) were also performed to detect the enzyme released in PBS medium from $\alpha$-chymotrysin loaded scaffolds.

\subsection{Antimicrobial test}

E. coli and M. luteus bacteria were selected to evaluate the antimicrobial effect of CHX and PHMB loaded electrospun fibers. The bacteria had previously been grown aerobically to exponential phase in broth culture ( $5 \mathrm{~g} / \mathrm{L}$ beef extract, $5 \mathrm{~g} / \mathrm{L} \mathrm{NaCl}, 10 \mathrm{~g} / \mathrm{L}$ peptone, $\mathrm{pH}$ 7.2).

Growth experiments were performed on a 24-well culture plate. Square pieces $\left(0.5 \times 0.5 \times 0.1 \mathrm{~mm}^{3}\right)$ of the electrospun scaffolds were placed into each well. Then, $1 \mathrm{~mL}$ of broth culture containing $10^{3} \mathrm{CFU}$ was seeded on the electrospun fiber mats. The cultures were incubated at $37{ }^{\circ} \mathrm{C}$ and agitated at $200 \mathrm{rpm}$. Aliquots of $50 \mu \mathrm{l}$ were taken at predetermined time intervals for absorbance measurements at $650 \mathrm{~nm}$ in a plate reader. Thus, turbidity was directly related to bacterial growth.

Bacterial adhesion onto scaffolds was also determined. The culture media were aspirated after incubation and the material was washed once with distilled water. Then, $0.5 \mathrm{~mL}$ of sterile $0.01 \mathrm{M}$ sodium thiosulfate was added to each well. After addition of $4 \mathrm{~mL}$ of broth culture, the plate was incubated at $37^{\circ} \mathrm{C}$ and agitated at $200 \mathrm{rpm}$ for $24 \mathrm{~h}$. The bacterial number was determined as indicated above. All assays were conducted in triplicate and the results were averaged.

Scaffolds were fixed with $2.5 \% \mathrm{w} / \mathrm{v}$ formaldehyde at $4{ }^{\circ} \mathrm{C}$ overnight. Then, they were washed three times with distilled water and Gram stained for observation by light microscopy.

\subsection{Cell adhesion and proliferation assays}

Cos-7 and Vero cells were cultured in Dulbecco's modified Eagle medium (DMEM) as previously reported [52].

Square pieces $\left(0.5 \times 0.5 \times 0.1 \mathrm{~mm}^{3}\right)$ of the electrospun scaffolds were placed and fixed in each well of a multiwell culture plate with a small drop of silicone (Silbione ${ }^{\circledR}$ MED ADH 4300 RTV, Bluestar Silicones France SAS, Lyon, France). They were then sterilized by UV-radiation in a laminar flux cabinet for $15 \mathrm{~min}$. For the cell adhesion and proliferation assays, aliquots of $50-100 \mu \mathrm{L}$ containing $5 \times 10^{4}$ cells were seeded onto the electrospun samples in each well and incubated for $24 \mathrm{~h}$ (adhesion assay) or 4 days (proliferation assay).

Samples were evaluated by the standard adhesion and proliferation method [52] using three replicates and the results were averaged. Samples with adhered and grown cells on the mats were fixed with $2.5 \% \mathrm{w} / \mathrm{v}$ formaldehyde at $4{ }^{\circ} \mathrm{C}$ overnight. They were subsequently dehydrated and processed for observation by scanning electronic microscopy.

\section{Results and discussion}

\subsection{Electrospinning of poly(ester urea) $1 \mathrm{~L} 6$}

In order to select the most appropriate conditions to obtain continuous 1L6 microfibers, several solvents and binary mixtures were tested at

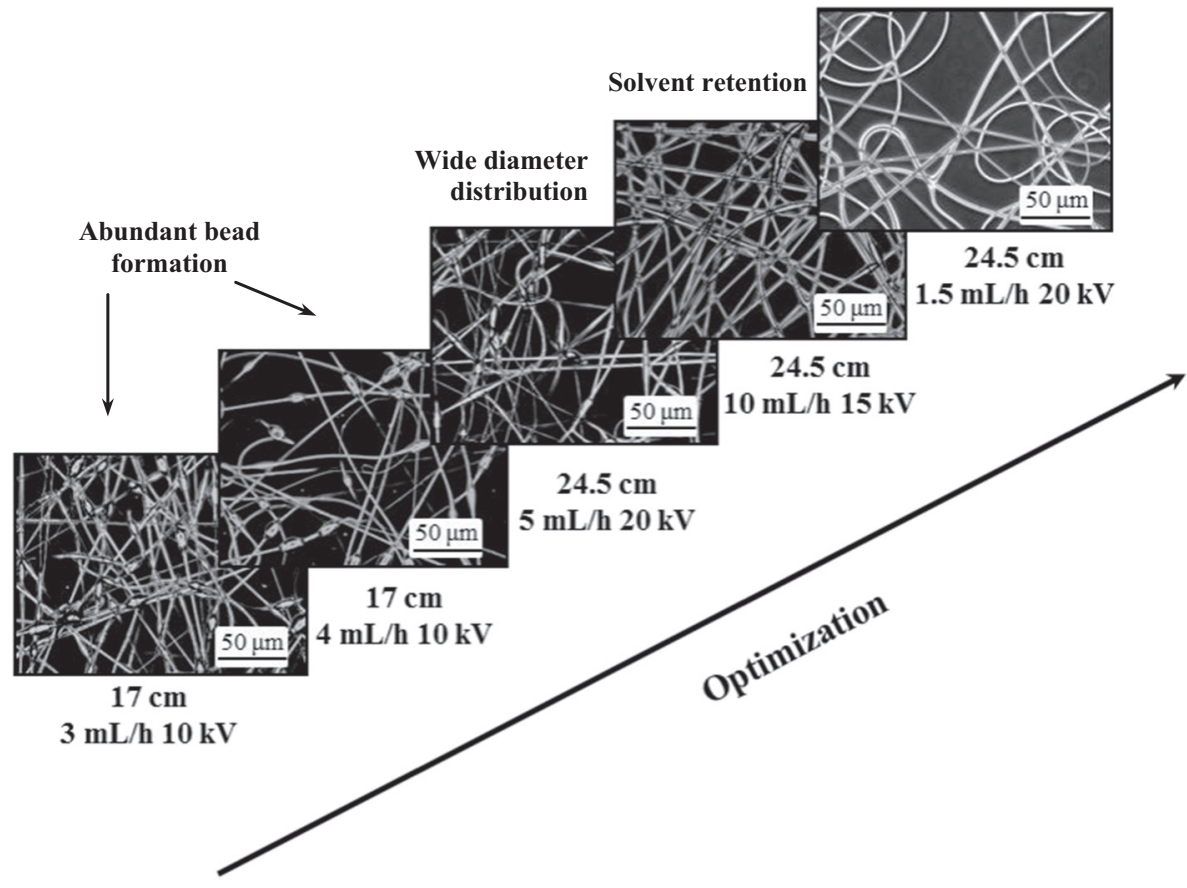

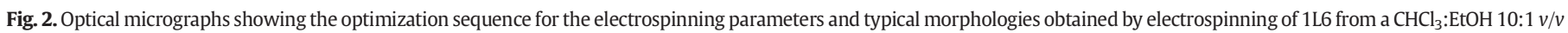
mixture and a polymer concentration of $18 \mathrm{wt} . \%$. 
different voltages, flow rates, polymer concentrations and needle tipcollector distances. Selection of the appropriate solvent is fundamental for continuous microfiber production [53,54], with a relatively high polymer concentration being generally required to avoid the formation of droplets and electrospun beads, especially when a good solvent is chosen [55].

1L6 has good solubility in most organic solvents (e.g. chloroform, ethanol and dimethylformamide), but the best results were attained using a $\mathrm{CHCl}_{3}: \mathrm{EtOH} 10: 1 \mathrm{v} / \mathrm{v}$ mixture and even when methanol was employed instead of ethanol. Polymer concentration in the ethanol mixtures had to be higher than $18 \mathrm{wt} . \%$. The high molecular weight of the poly(ester urea) facilitated the electrospinning process and, in fact, continuous microfibers were obtained under a wide range of processing conditions (i.e. needle tip-collector distance, flow rate and voltage). Fig. 2 is an example of the optimization process as followed by optical microscopy which shows that good fibers could be attained in most test conditions.
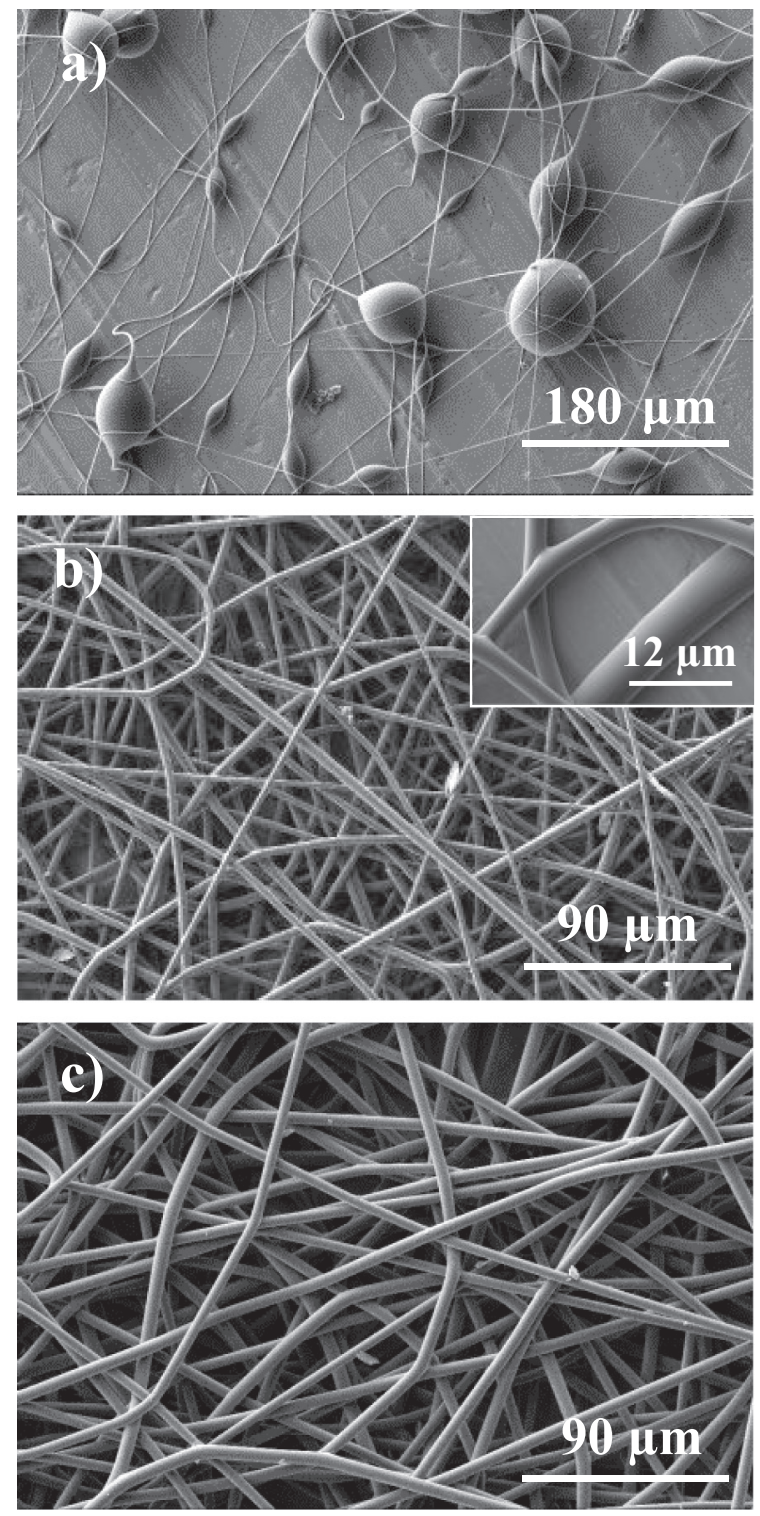

Fig. 3. SEM micrographs of electrospun microfibers obtained from a $\mathrm{CHCl}_{3}: \mathrm{EtOH} 10: 1 \mathrm{v} / \mathrm{v}$ mixture using different voltages, needle tip-collector distances, polymer concentrations

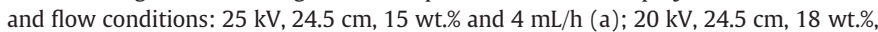
and $1.5 \mathrm{~mL} / \mathrm{h}(\mathrm{b}) ; 25 \mathrm{kV}, 24.5 \mathrm{~cm}, 20 \mathrm{wt} . \%$ and $5 \mathrm{~mL} / \mathrm{h}$ (c). Insets show high magnification images (scale bar $4 \mu \mathrm{m}$ ) for observation of fiber surface details.
Representative SEM micrographs showing different morphologies are given in Fig. 3. Polymer concentration was varied to illustrate the formation of droplets and very thin nanofibers (Fig. 3a) at concentrations lower than the above value. At higher values, microfibers were quite similar despite significant differences in conditions (Fig. 3b and c). Long microfibers with a cylindrical morphology and randomly distributed in the fibrous mats were generally formed. Under optimal process conditions, fibers had a dense but porous structure, a relatively narrow monomodal distribution and an average diameter size of $2.70 \mu \mathrm{m}$ (Fig. 4, Table 2). They were also characterized by a porous surface texture, as shown in high magnification images (Fig. 4b).

Electrospinning could also be performed without changing the operational parameters upon incorporation of CHX and PHMB into the polymer solution. CHX loaded electrospun fibers were highly similar to the unloaded samples while incorporation of PHMB resulted in significantly smaller fiber diameters (i.e. from 2.70 to $1.20 \mu \mathrm{m}$ ) (Fig. 5a and b, Table 1). This indicated a drastic change in the physicochemical characteristic of the electrospinable solution caused by the presence of polymeric biguanide. No significant changes were found in the fiber
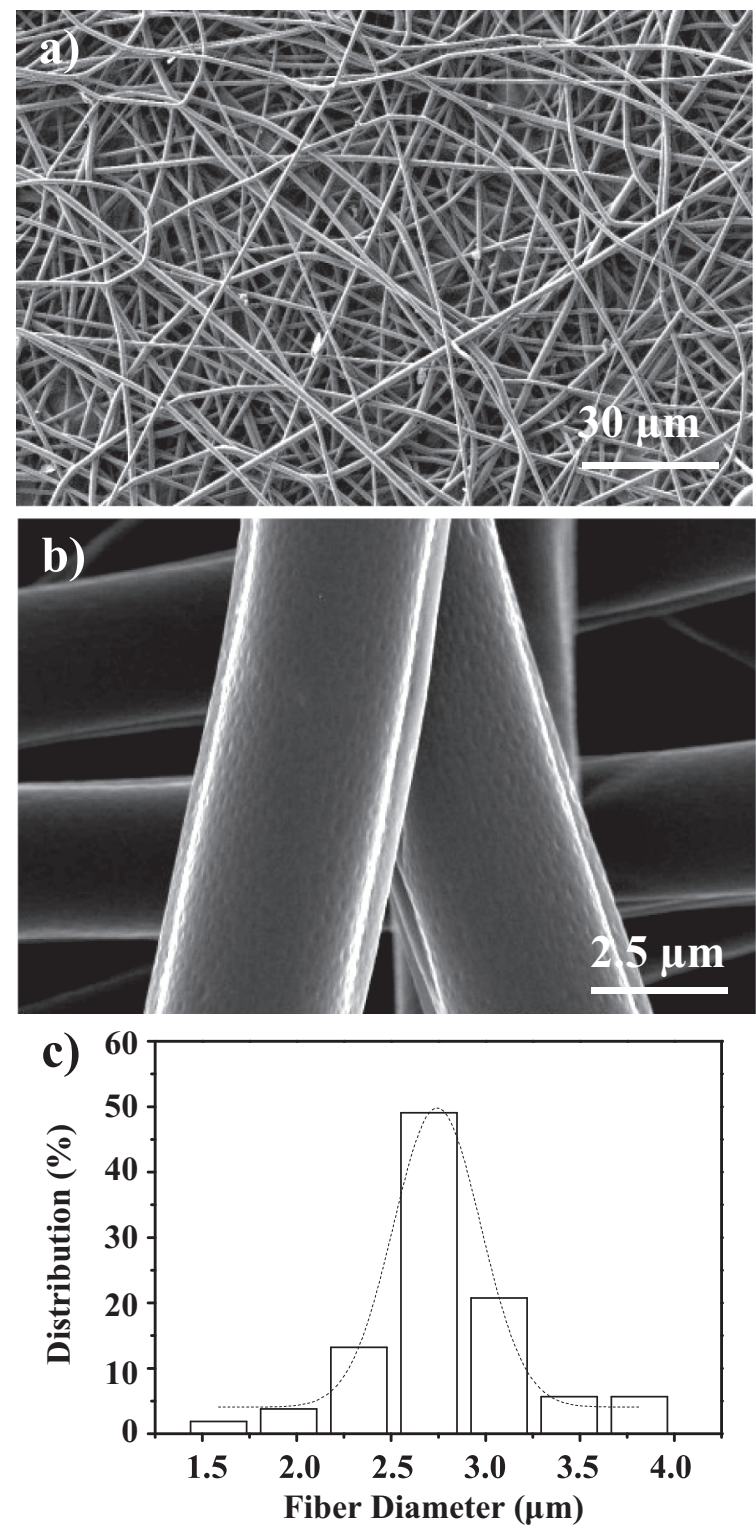

Fig. 4. SEM micrographs of 1L6 electrospun microfibers under optimized conditions (a,b) and diameter distribution $(\mathrm{c})$ 
Table 2

Optimal electrospinning conditions for 1L6-CHX, 1L6-PHMB and 1L6- $\alpha$-chymotrypsin samples and average diameter size.

\begin{tabular}{|c|c|c|c|c|}
\hline Sample & $\begin{array}{l}\text { Voltage } \\
(\mathrm{kV})\end{array}$ & $\begin{array}{l}\text { Rate } \\
(\mathrm{mL} / \mathrm{h})\end{array}$ & $\begin{array}{l}\text { Distance } \\
(\mathrm{cm})\end{array}$ & $\begin{array}{l}\text { Diameter } \\
(\mu \mathrm{m})\end{array}$ \\
\hline $1 \mathrm{~L}^{\mathrm{a}}$ & 20 & 1.5 & 24.5 & $2.70 \pm 0.11$ \\
\hline $1 \mathrm{~L} 6-\mathrm{CHX}^{\mathrm{a}}$ & 20 & 1.5 & 24.5 & $2.64 \pm 0.14$ \\
\hline 1L6-PHMB ${ }^{\mathrm{a}}$ & 20 & 1.5 & 24.5 & $1.20 \pm 0.05$ \\
\hline 1 L6- $\alpha$-Chymotrypsin ${ }^{\mathrm{b}}$ & 25 & 0.5 & 24.5 & $0.458 \pm 0.15$ \\
\hline
\end{tabular}

a From solutions containing 18 wt.\% of PEU.

b From solutions containing 13 wt.\% of PEU.

surface since a porous texture was detected in both kinds of drug loaded samples.

\subsection{Hydrophobicity of 1 L6 samples}

Although wettability of materials depends mostly on both surface energy and roughness, the latter is the key factor after selecting their components. Therefore, hydrophobicity may vary significantly with the form (melt processed film or electrospun scaffold) of the material, and even be affected by incorporation of a drug. Fig. 6 shows the water contact angle values of 1L6 films and scaffolds, as well as CHX and PHMB loaded scaffolds.

The contact angle of the 1L6 microfiber scaffold increased drastically compared to that of the film (i.e. from $89 \pm 4^{\circ}$ to $127^{\circ}$ ) since deposition of microfibers led to a much greater surface roughness than expected for a film sample.

The impact of roughness on the contact angle is given by the Wenzel equation: [56]

$\cos \theta_{W}=r \cos \theta_{Y}$

which relates the contact angle of a rough surface, $\theta_{W}$, with the roughness ratio of the surface, $r$, and the contact angle of a smooth surface, $\theta_{Y}$.

The Wenzel equation shows that contact angles on hydrophobic surfaces increase with surface roughness for a water droplet because the ratio between the true surface area of a rough surface and that of a
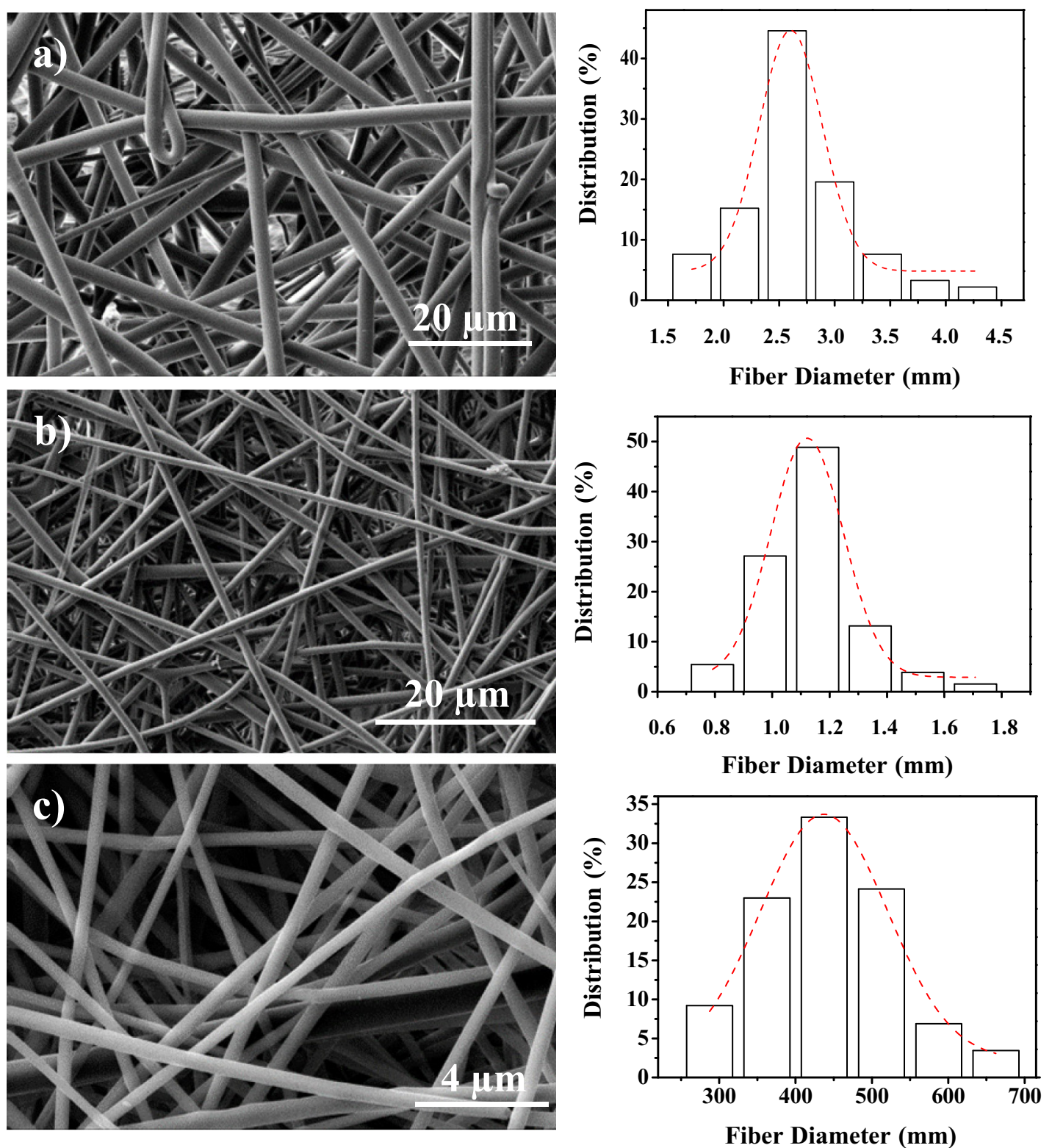

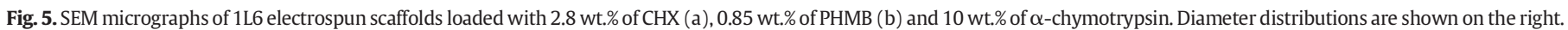




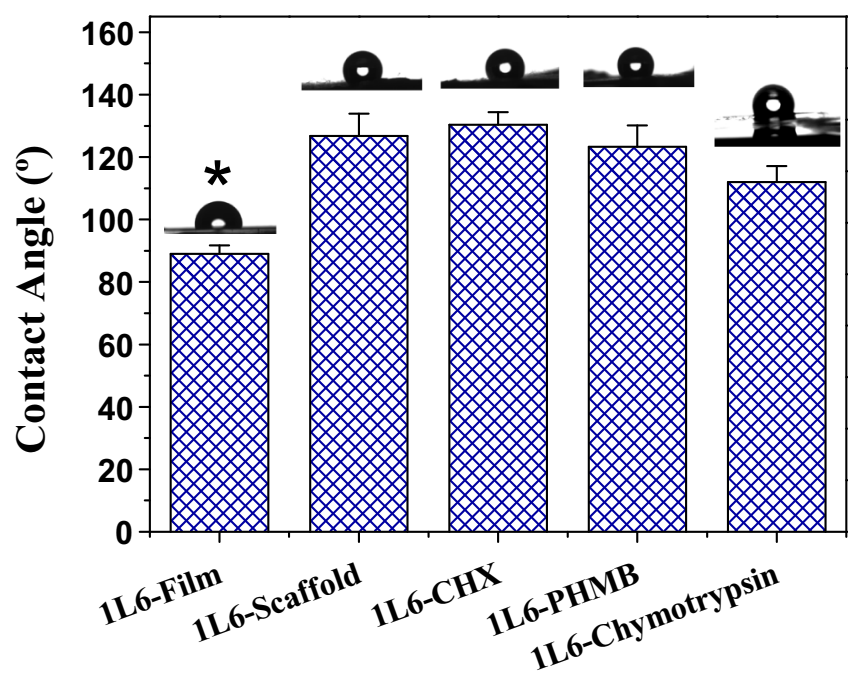

Fig. 6. Contact angles for 1L6 films and scaffolds unloaded and loaded with CHX, PHMB and $\alpha$-chymotrypsin.

comparably sized smooth surface is always greater than one. The measured value for the smooth $1 \mathrm{~L} 6$ film was close to $90^{\circ}$ which is strictly the lower limit value for a hydrophobic substance.

The high increase of the contact angle seems however difficult to be justified by the typical Wenzel equation and consequently microfiber scaffolds seem to benefit from air pocket formation. Therefore, the Cassie-Baxter equation [57] should also be considered:

$\cos \theta_{w}=f_{1} \cos \theta_{1}+f_{2} \cos \theta_{2}$

where $f_{1}$ represents the fraction of each component (polymer and air) and $\theta_{1}$ is the corresponding contact angles. When $f_{2}$ represents the area fraction of trapped air, Eq. (2) can be modified according to simple Eq. (3):

$\cos \theta_{w}=f \cos \theta_{Y}+(1-f) \cos 180^{\circ}=f \cos \theta_{Y}+f-1$

where $f$ is an area fraction of the solid-liquid interface and $(1-f)$ is that of the air-liquid interface which contact can be considered to be $180^{\circ}$.

The contact angles of antibacterial drug loaded scaffolds and the unloaded 1L6 scaffold were highly similar. Thus, the small change in roughness/porosity caused by the lower fiber diameter (e.g. for PHMB loaded samples) or the hydrophilic character of loaded drugs had a minimum impact.

\subsection{Degradation of poly(ester urea) 1 L6 films and scaffolds}

Weight loss in the three media (i.e. lipase, proteinase K and Chymotrypsin) during enzymatic degradation is plotted in Fig. 7 for meltprocessed films of the studied poly(ester urea). As can be seen, all values are higher than $50 \%$ after only 15 days of exposure to the media, demonstrating the susceptibility of the 1L6 sample to enzymatic attack. However, a significant delay in the last stages of degradation was observed in the lipase medium. In fact, degradation was still similar after 21 days of exposure to both $\alpha$-chymotrypsin and proteinase $\mathrm{K}$ media. Weight loss reached a value close to $80 \%$ before films became completely brittle. Note also that weight loss was practically linearly dependent on the exposure time to both media. On the contrary, linearity was progressively lost after an initial period, and the maximum level of degradation $(80 \%)$ was reached after 31 days in the lipase medium. These results suggest the ability of proteinase $\mathrm{K}$ and $\alpha$-chymotrypsin to degrade ester groups as well as $\mathrm{CO}-\mathrm{NH}$ linkages of the urea group. By contrast, lipase was only effective with the ester linkages, causing a slightly

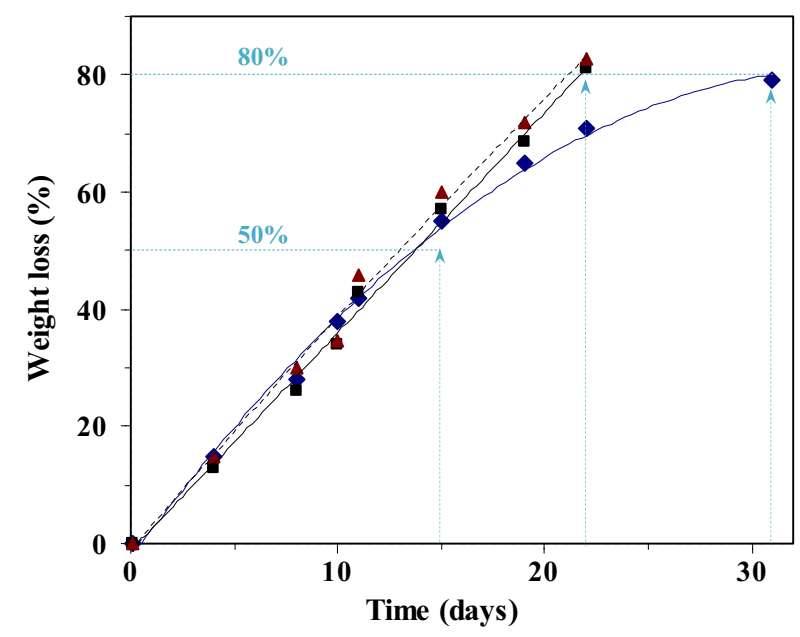

Fig. 7. Plots of weight loss versus exposure time for $1 \mathrm{~L} 6$ films exposed to proteinase $\mathrm{K}(\boldsymbol{\square})$, $\alpha$-chymotrypsin $(\boldsymbol{\Delta})$ and lipase $(\bullet)$ media.

delayed degradation that became more evident at the end of the process where more resistant urea enriched fragments should be predominant. Degradation was also evaluated in PBS control solution because in this case only hydrolytic attack was expected. Results (not shown) indicate a weight loss of less than $5 \%$ after 31 days of exposure.

SEM micrographs taken after exposure of film samples to the degradation media show that degradation progressed steadily on their surface, with abundant formation of deep cracks (e.g. Fig. 8b). This contrasts with the practically unaltered surface of samples exposed to a non-enzymatic PBS hydrolytic medium for a similar period (Fig. 8a). High magnification images (Fig. $8 \mathrm{c}$ and d) also reveal that enzymatic degradation eroded the samples without retention of degradation products, suggesting their release in the media.

Fig. 9 shows the weight loss evolution of 1L6 electrospun scaffolds that were fully immersed in the degradation media. In all cases, degradation progressed very fast during the first three days of exposure (e.g., weight loss was higher than $60 \%$ ) and subsequently a steady evolution at a lower degradation rate was detected (e.g. weight loss was close to 90-95\% after 10 days). Minor differences were observed between samples exposed to the three different enzymatic media. Polymers logically appeared to be more easily degraded in microfiber than in film form, especially at the beginning of exposure.

Fig. 10 shows SEM micrographs of the scaffold during the enzymatic attack. It is clear that only the fibers placed on the surface of the scaffold were degraded at the beginning (Fig. 10a) due to the high hydrophobicity of the sample that prevented the access of the aqueous medium to the inner parts of the scaffold, which remained practically unaltered. Obviously, the internal fibers become accessible to enzymes as the fibers placed on the surface were degraded (Fig. 10b), being this process slower than the initial step concerning the outer fibers. A practically complete degradation was reached after 10 days as shown in Fig. 10c.

High magnification micrographs revealed some differences on the texture of degraded fibers. Note for example that fibers exposed to proteinase K seemed to retain more degradation products (Fig. 10f), a feature that may be related to the slightly lower weight loss observed in this medium. These products were less evident during exposure to lipase medium and specifically a clear erosion of minority beads was detected (Fig. 10e).

It is interesting to note that scaffolds tend to float on the medium and consequently degradation could be clearly delayed by the wettability effect as shown in Fig. 9 for a scaffold exposed to proteinase K medium without a forced immersion. 

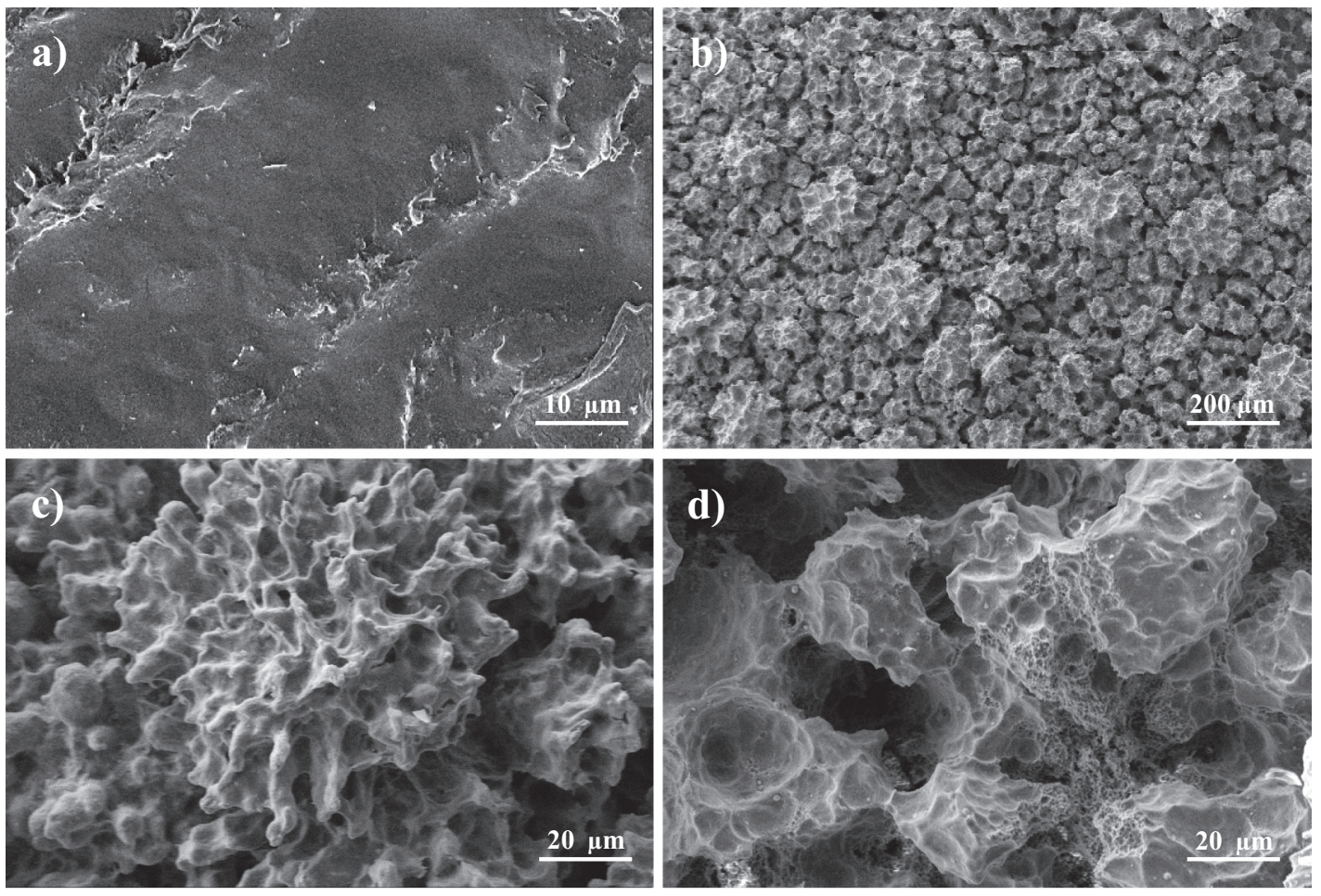

Fig. 8. Scanning electron micrographs of $1 \mathrm{~L} 6$ films after 19 days of exposure to PBS (a), $\alpha$-chymotrypsin (b,d) and lipase (c) media at $37^{\circ} \mathrm{C}$.

3.4. Poly(ester urea) 1L6 electrospun scaffolds loaded with $\alpha$-chymotrypsin as a degrading enzyme

The high solubility of 1L6 allowed the choice of the appropriate combination of solvents to perform the electrospinning process and dissolve potentially degrading enzymes without a remarkable inactivation/denaturation effect. $\alpha$-Chymotrypsin was selected as the degrading enzyme on account of its higher effectiveness, as found in the degradation experiments with film samples. To avoid protein denaturation, methanol was preferred to ethanol; specifically a $\mathrm{CHCl}_{3}: \mathrm{CH}_{3} \mathrm{OH}$ 9:4 v/v mixture and a polymer concentration of $13 \mathrm{wt}$.\% were used. A high enzyme concentration ( $1.5 \mathrm{w} / \mathrm{v} \%$ ) was also employed to ensure incorporation of a reasonable proportion of enzymes (i.e. $10 \mathrm{wt} . \%$ ) with a suitable activity within nanofibers. Electrospinning conditions were optimized

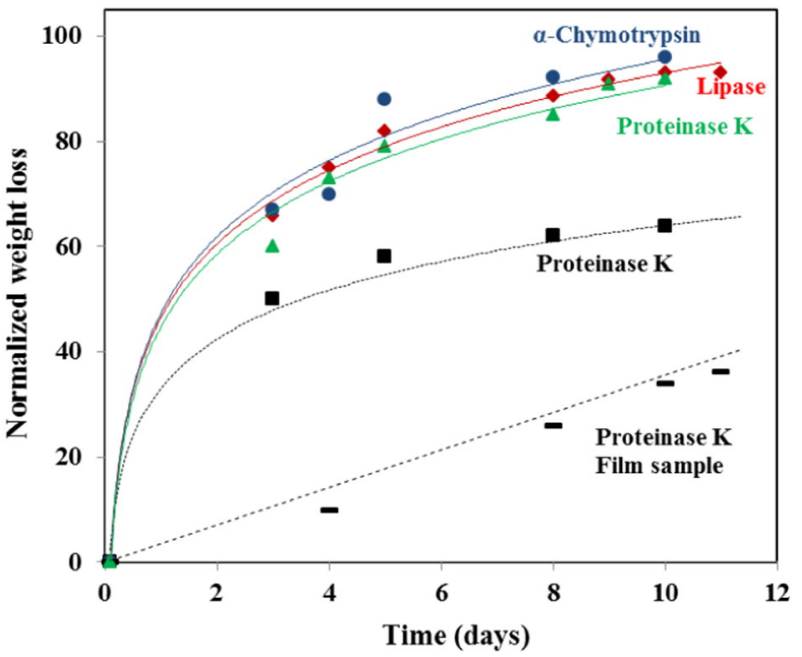

Fig. 9. Plots of weight loss versus exposure time for $1 \mathrm{~L} 6$ scaffolds exposed to proteinase $\mathrm{K}$ $(\boldsymbol{\Delta}) \alpha$-chymotrypsin $(\bullet)$ and lipase $(\bullet)$ media. For comparative purposes degradation data in a proteinase $\mathrm{K}$ medium are also given for a $1 \mathrm{L6}$ film $(-)$ and a not fully immersed 1L6 scaffold (匹). under these new values and some parameters should be significantly varied, as indicated in Table 2 . The most drastic change affected the flow rate, which had to be significantly decreased to obtain continuous and homogeneous fibers (Fig. 5c). Solvent evaporation was enhanced and the average value of fiber diameters (i.e. $458 \mathrm{~nm}$ ) was lower than of ethanol containing mixtures and higher flow rates. In this case, contact angle measurements (Fig. 6) indicated a slight decrease in hydrophobicity compared to the unloaded scaffold. The large amount of loaded enzyme and the significant reduction in fiber diameter are worth noting.

New scaffolds appear highly interesting because of their incorporation of agents, which could accelerate the degradation process and tissue regeneration. Cell colonization could be enhanced by the formation of a more porous structure and loss of the supporting synthetic polymer. Since electrospun nanofibers have good characteristics (e.g. size and surface morphology) to be enzyme immobilization supports, several works have focused on achieving enzyme immobilization via covalent attachment [58]. The simpler approach consisting in the incorporation of enzymes (including $\alpha$-chymotrypsin and lipase) into the polymers was previously demonstrated for $\alpha$-amino acidbased poly(ester amide)s [59]. The present approach is similar because the enzyme is directly incorporated in 1L6 during the electrospinning process.

Micrographs in Fig. 11a reveal the degradation of scaffolds exposed to a pH 7.4 sodium phosphate buffer at $37{ }^{\circ} \mathrm{C}$ without a forced immersion and after only 2 days of exposure. More interestingly, only nanofibers on the outer surface of the scaffold (i.e. those in direct contact with the aqueous medium) are degraded. Furthermore, the process mainly affects the inner part of fibers, where the maximum amount of enzyme is loaded. As can be seen in the higher magnification image (Fig. 11b), fibers appear longitudinally cracked or even as if they had exploded and only their skin remained. The SEM micrograph clearly demonstrated that enzymatic attack took place by simple exposure of the $\alpha$ chymotrypsin loaded fiber to the aqueous medium in contrast to the low erosion detected when unloaded fibers were exposed to PBS (not shown). The micrograph shows also that degradation products seemed to be partially retained in the fibers due to their high insolubility. UV 

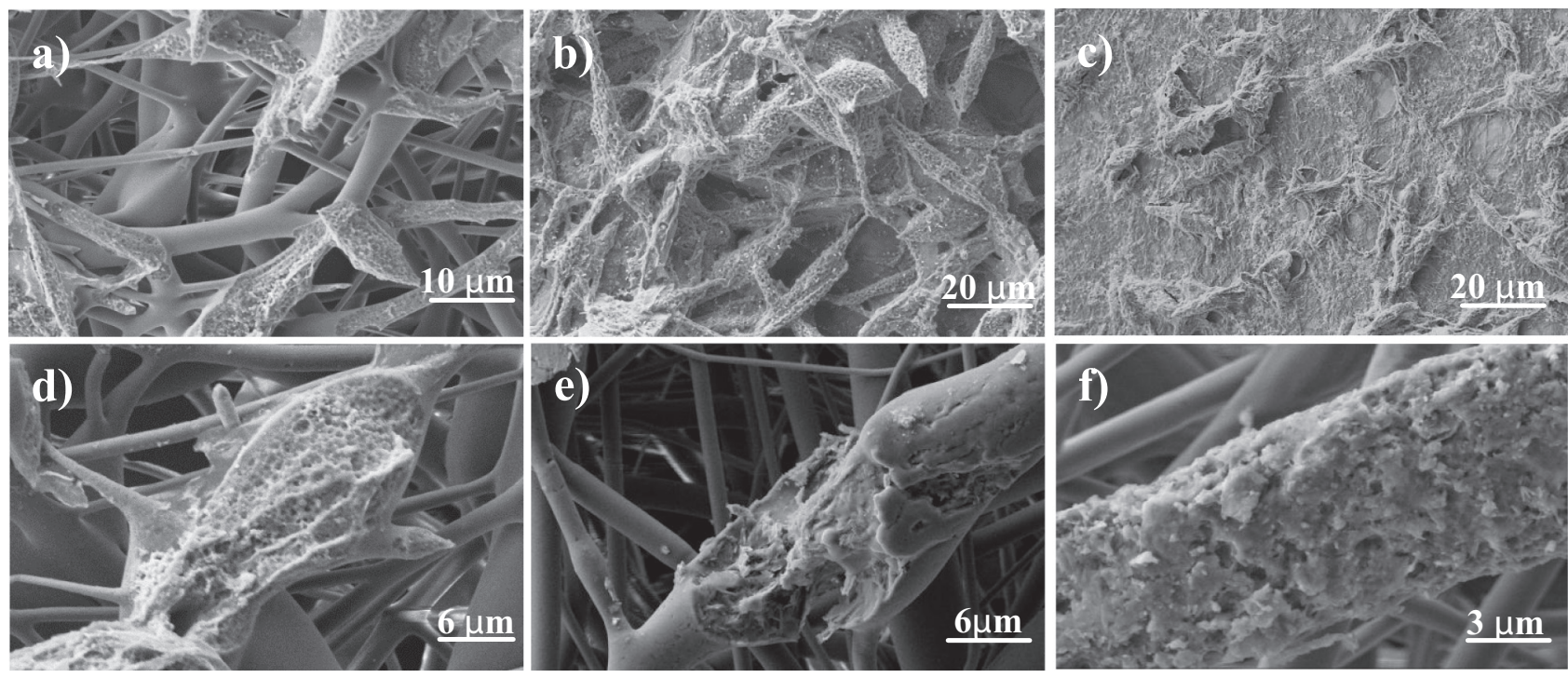

Fig. 10. Scanning electron micrographs of $1 \mathrm{~L} 6$ scaffolds after exposure to $\alpha$-chymotrypsin (a,b,c,d), lipase (e) and proteinase $\mathrm{K}$ (f) media at $37^{\circ} \mathrm{C}$ for 3 (a,d,e,f), 6 (b) and 8 (c) days.

absorbance measurements (282 $\mathrm{nm}$ ) indicate that no $\alpha$-chymotrypsin was released to the PBS degradation medium after 3 days of exposure. Thus, enzymes were effectively retained in the scaffold when exposed to a hydrophilic medium.

Also interesting is the high hydrophobicity of the scaffold surface (Fig. 6), which caused a progressive degradation that should evolve from the outer to the inner surface. Thus, the scaffold should retain its structural function for longer than expected when all fibers were equally accessible to water molecules and started to degrade at the same time.
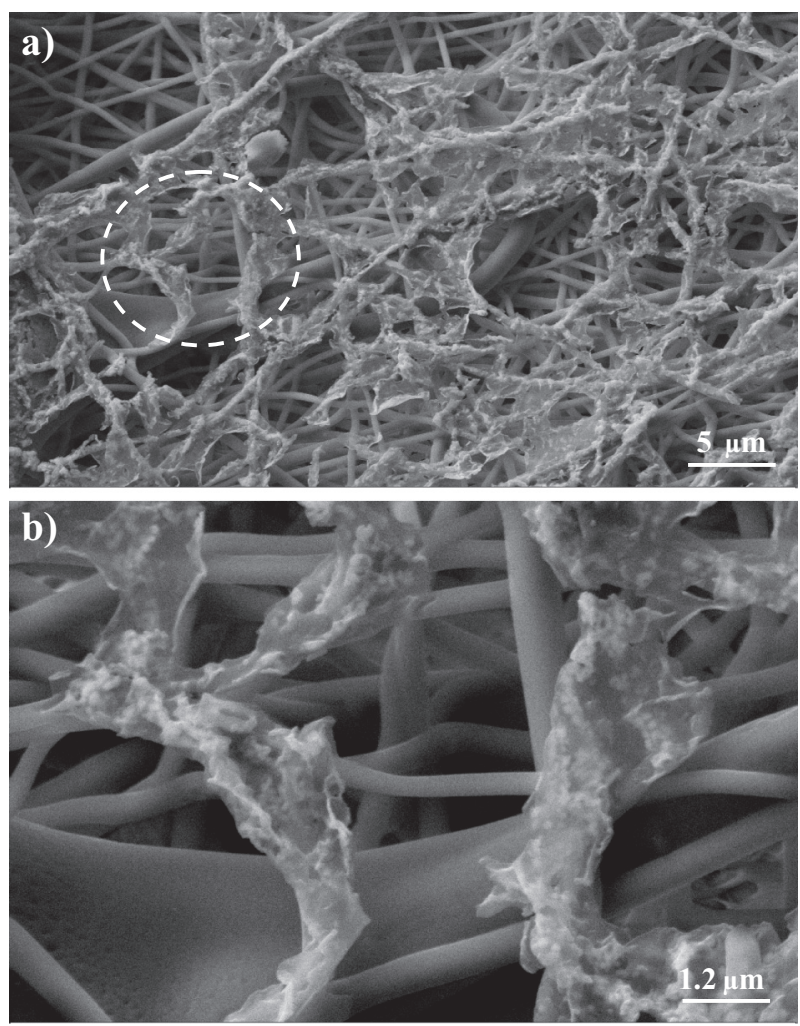

Fig. 11. Scanning electron micrographs at different magnifications of $1 \mathrm{~L} 6$ scaffolds loaded with 10 wt.\% of $\alpha$-chymotrypsin after 2 days of exposure to PBS medium at $37{ }^{\circ} \mathrm{C}$.

\subsection{Biguanide release from $1 \mathrm{~L} 6$ scaffolds}

The release of biguanide compounds from an electrospun matrix is intimately related to the morphology and structure of constituent fibers and to the release environment. In fact, the rate of diffusion-controlled drug release depends on three main factors: a) Solubility of the drug in the release medium, b) ability of the medium to penetrate the polymer matrix, and c) physical interactions between the polymer and drug [60].

The release of CHX and PHMB from 1L6 scaffolds was studied in media with different hydrophobicity/hydrophilicity ratios (i.e. PBS and PBS-EtOH 3:7 v/v mixture). Specifically, ethanol is more hydrophobic than water and has higher affinity with 1L6. PBS-EtOH may also have a swelling effect that facilitated drug delivery. The release behavior of both drugs in the two media was clearly different, i.e. a maximum release of 3\% in PBS (data not shown) versus $91 \%$ in the mixture of solvents after an exposure of only $90 \mathrm{~h}$ (Fig. 12).

Logically, differences in release behavior between CHX and PHMB were insignificant in the more hydrophobic medium. In fact, the release of PHMB was slightly delayed during the first $10 \mathrm{~h}$ of exposure, probably

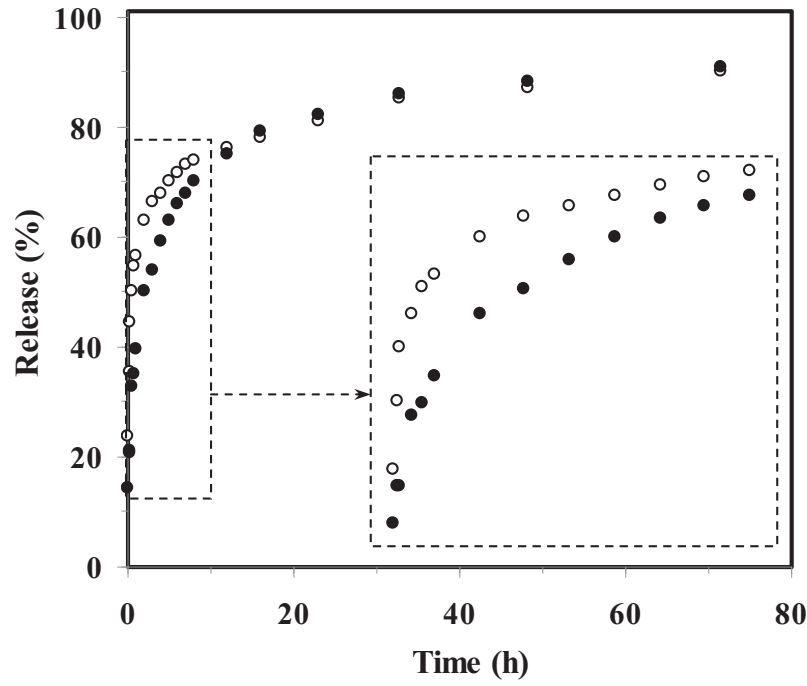

Fig. 12. Drug release profiles of $1 \mathrm{~L} 6$ scaffolds loaded with $0.05 \mathrm{wt} . \%$ of $\mathrm{CHX}(\mathrm{O})$ and 0.015 wt.\% of PHMB ( ) in PBS-EtOH 3:7 v/v. 
due to its higher molecular weight, which hindered diffusion through the microfiber, and even to its slightly higher hydrophilicity. Nevertheless, measurements indicate a rapid release of both drugs from electrospun scaffolds in a media with similar hydrophobicity than physiological serum-containing medium, and consequently a rapid antibacterial effect should be expected.

\subsection{Antibacterial assays of biguanide loaded 1 L6 scaffolds}

The antibacterial effect of CHX and PHMB released from microfiber scaffolds was determined by studying bacterial growth inhibition in broth culture. Unloaded 1L6 scaffolds appeared highly susceptible to bacterial colonization, with bacterial growth levels similar to that of the positive control (polystyrene plate), as can be seen in Fig. 13. Colonization can be effectively avoided by loading a low PHMB and CHX ratio, as also shown in Fig. 13. Thus, a significant decrease in the number of both Gram-positive (M. luteus) and Gram-negative (E. coli) bacteria was observed in drug loaded scaffolds compared to the control and the unloaded scaffold. The greatest decrease was found for the high molecular weight of PHMB (i.e. 97-95\% versus 76-79\% for PHMB and CHX, respectively).

It should be pointed out that the number of active biguanide groups in the CHX and PHMB loaded scaffolds was similar because drug content was specifically selected to this end. Furthermore, differences cannot be attributed to a different release behavior, as explained above, and even a slightly lower release rate was observed for PHMB. This suggests a higher antimicrobial activity of biguanides in polymeric form, as has also been reported [51]. In fact, the high effectiveness has been related to a novel mechanism of action based on the interaction of PHMB with nucleic acids that led to co-precipitation. At low bacteriostatic concentrations, the damage caused by this interaction could be tolerable and the antibacterial effect would be due to disruption of the cell membrane, as usually expected [33]. However, because the binding between PHMB and DNA is highly cooperative, a slightly higher drug dose can cause massive perturbation of DNA function and/or precipitation leading to cell death. An additional advantage of PHMB over CHX is that a lower wt.\% is required for similar biguanide contents. Logically, the electrospinning conditions should be less affected, and moreover drug activity can be increased by loading a higher amount of PHMB (e.g. just that corresponding to $\mathrm{CHX}$ wt.\%).

The effect of CHX and PHMB on studied bacteria was similar due to the wide antibacterial spectrum of both drugs (Fig. 13). It is highly interesting that CHX and PHMB could be loaded into the 1L6 microfibers by electrospinning without loss of antimicrobial activity. Hence, solvent or

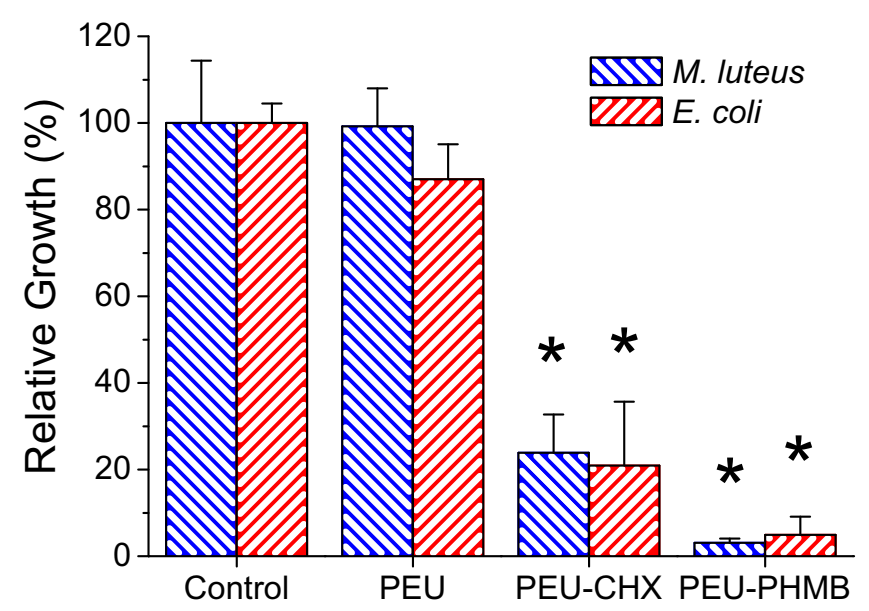

Fig. 13. Escherichia coli and Micrococcus luteus bacterial growth in 1L6 scaffolds loaded with CHX and PHMB and the positive control. The bars are mean \pm SD $(n=4)$. ${ }^{*} p<0.05$ vs. control, ANOVA followed by Tukey test. high voltage did not cause any adverse effect, allowing easy preparation of scaffolds with an added value (e.g. antibacterial activity).

\subsection{Biocompatibility of films and scaffolds of the poly(ester urea) $1 \mathrm{L6}$}

Adhesion and proliferation tests of epithelial (Vero) and fibroblast (Cos-7) cells were performed on 1 L6 films and scaffolds. These assays are useful in following cell development because adhesion is an early cellular event and proliferation is an evidence of metabolic cell activity. While adhesion of both cell lines on scaffolds and the control was rather similar, significant differences were detected between scaffolds and films (Fig. 14a). Viability was significantly lower for films, especially the Vero cell line ones. This result is interesting because it reflects the effect of increased porosity of the scaffold sample (i.e. a 3D-structure more favorable for rapid cell colonization), which is even sufficient to counterbalance the negative effect of its higher hydrophobicity. Proliferation assays gave similar results, as depicted in Fig. 14b, although enhancement of cell proliferation compared to the film was similar for both Cos-7 and Vero cell line scaffolds.

Representative micrographs of morphological characteristics of cell growth on 1L6 films are shown in Fig. 15. Fibroblast (Cos-7) and epithelial (Vero) cells formed monolayers on the 1L6 film surface (Fig. 15a and e) structured with close interactions between neighboring cells to form a tissue (see arrows in Fig. 15b and f). Furthermore, cell adhesion on the film surface promoted the formation of intercellular bridges (see double arrows in Fig. $15 \mathrm{c}$ and g). These bridges correspond to filopodia developed from an early attachment (h), as evidenced by the rounded
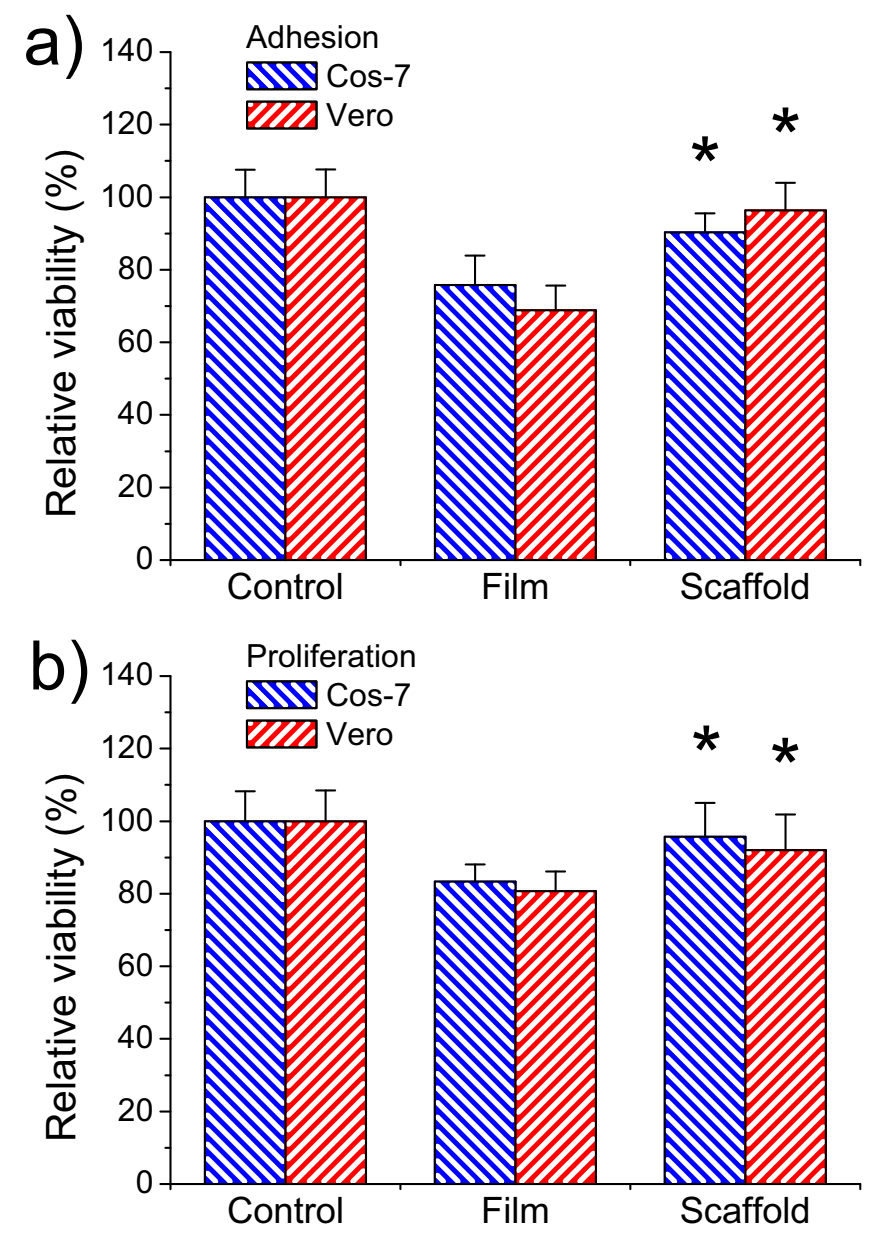

Fig. 14. Biocompatibility of PEU matrices determined by cell adhesion (a) and proliferation (b) of fibroblast (Cos-7) and epithelial (Vero) cells. The bars are mean \pm SD $(n=4)$. ${ }^{*} p<0.05$, scaffold vs. film, ANOVA followed by Tukey test. 

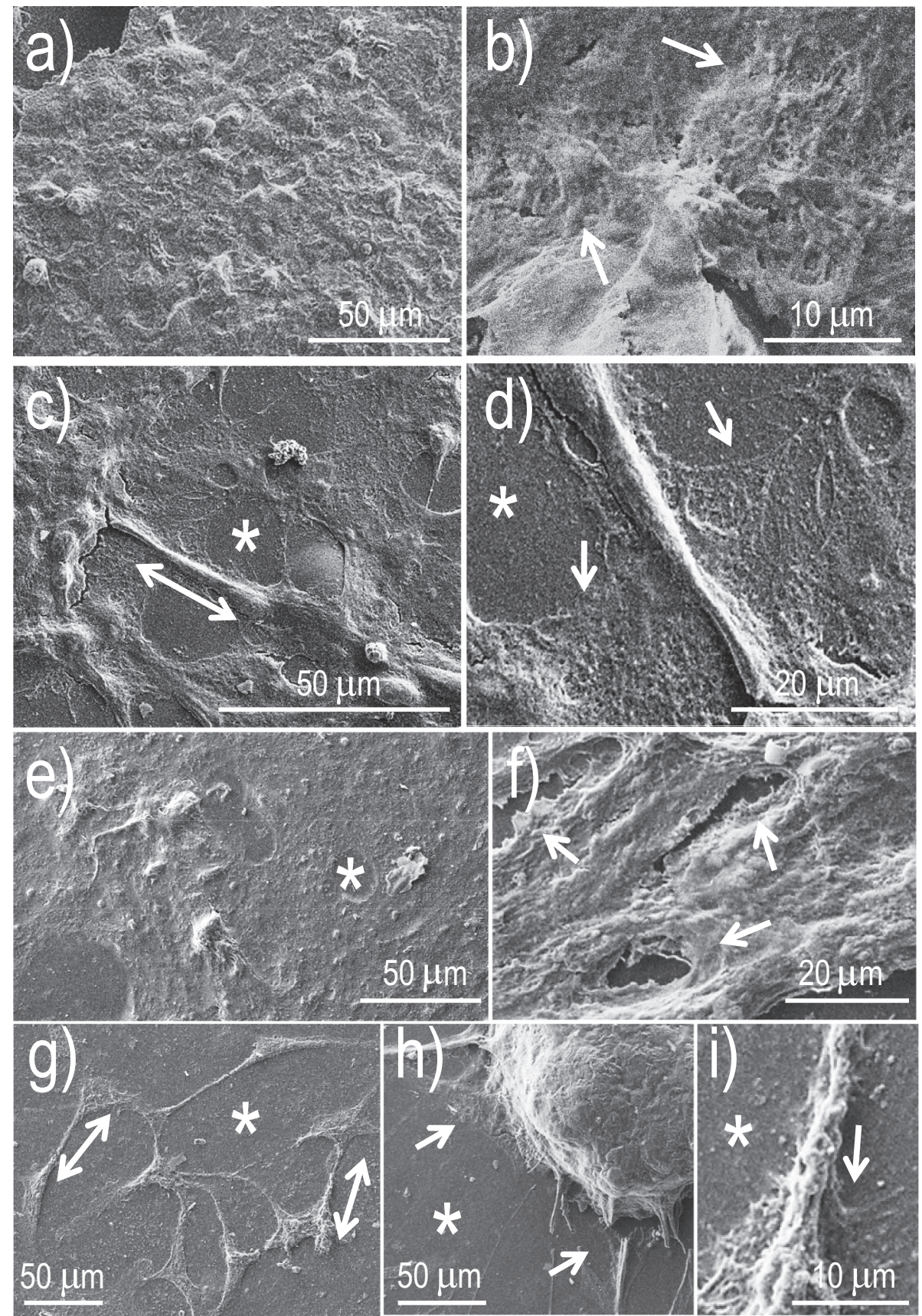

Fig. 15. Morphological characteristics of cell growth (fibroblast (Cos-7) cells (a-d) and epithelial (Vero) cells (e-i)) in 1L6 films.

shape of cells. Moreover, the free surface of the material made it possible to obtain a broad extension of cell cytoplasm through lamellipodia (named cell spreading), which are auxiliaries for cell attachment onto the material surface through filopodia (see arrows in Fig. 15d and i).

Micrographs in Fig. 16a and g show that both types of cells were also competent to form monolayers over the fiber matrices. Fiber tracks can be clearly seen below the Cos-7 cell monolayer (Fig. 16a) whereas the tile morphology of Vero cells hinders their observation (Fig. 16g). Cos7 cells demonstrated their ability to invade the pores between fibers, forming a tissue-like structure (arrows in Fig. 16b) where cells were connected to each other by small filopodia (arrows in Fig. 16c). Material colonization occurred locally, as evidenced by the formation of interconnected cell clusters (arrows in Fig. 16d). The 1L6 scaffolds facilitated guided cell growth (Fig. 16e) and the establishment of cell connections through extensions of filopodia that cross over the pores of the matrix (arrows in Fig. 16f). Vero cells also grew over the polymer matrix in a guided manner through the fibers (arrows in Fig. 16h).

\section{Conclusions}

A new $\alpha$-amino acid containing poly(ester urea) was successfully electrospun to form microfiber scaffolds. Continuous fibers with a monomodal diameter distribution and slightly rough surface were formed under a wide range of electrospinning conditions. The high solubility of the PEU derived from L-leucine, 1,6-hexanediol and carbonic acid allowed the use of appropriate solvents to load different antibacterial drugs and even enzymes without being denatured.

The 1L6 poly(ester urea) films were more susceptible to enzymatic attack by proteases than by lipases because the latter mainly involved hydrolysis of ester groups. Despite these minor differences, both enzymes led to rapid degradation of film samples. 1L6 scaffolds degraded 

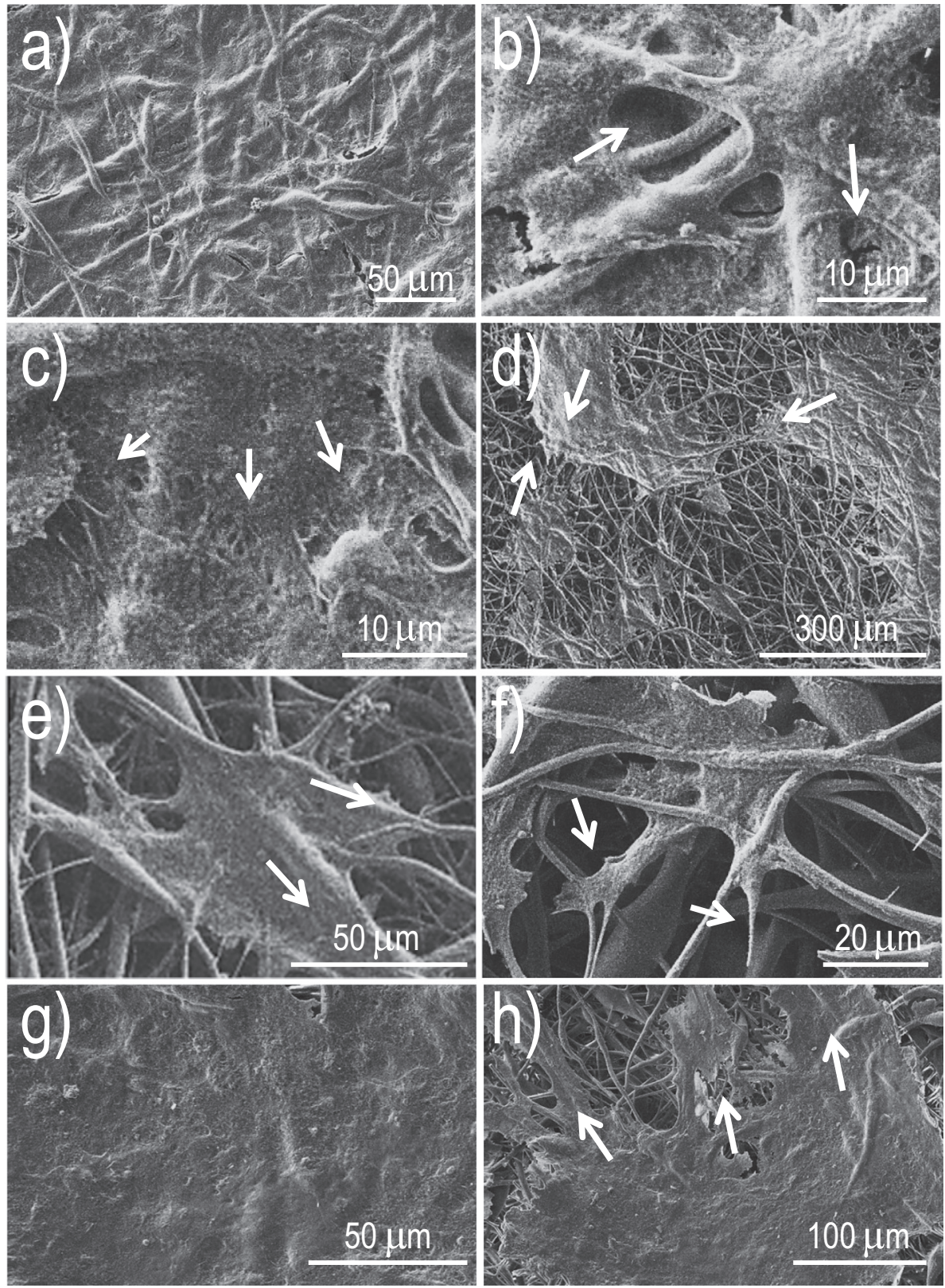

Fig. 16. Morphological characteristics of cell growth (fibroblast (Cos-7) cells (a-f) and epithelial (Vero) cells (g-h)) in 1L6 fiber matrices.

faster than films due to the greater surface area of constitutive fibers. The high hydrophobicity of 1L6 scaffolds had repercussions on enzymatic degradability since different weight loss rates were found depending on how samples were exposed to the medium (e.g. forced or non-forced immersion). In any case, hydrophobicity caused that inner fibers were well-preserved at least during the first three days of exposure.

Monomeric (CHX) and polymeric (PHMB) biguanide compounds were effectively loaded into the electrospun scaffolds. Slight differences in fiber morphology and antibacterial properties were found depending on the loaded drug. Specifically, PHMB led to narrow fibers and had an increased antibacterial effect against Gram-positive and Gramnegative bacteria. $\alpha$-Chymotrypsin could also be loaded into the 1L6 scaffolds, giving rise to materials with enzymes that could accelerate degradation and tissue regeneration.

Adhesion and proliferation of epithelial (Vero) and fibroblast (Cos7) cells on 1L6 films and scaffolds demonstrated the biocompatibility of the new poly(ester urea). Slight differences in cell viability were found, with films exhibiting the lower values. The effect of increased porosity of scaffold samples appears sufficient to counterbalance the negative effect of its higher hydrophobicity.

\section{Acknowledgments}

Authors are in debt to supports from MICINN and FEDER (MAT201236205) and the Generalitat de Catalunya (2009SGR1208).

\section{References}

[1] S.J. Huang, D.A. Bansleben, J.R. Knox, Biodegradable polymers: chymotrypsin degradation of a low molecular weight poly(ester-urea) containing phenylalanine, J. Appl. Polym. Sci. 23 (1979) 429-437.

[2] M. Yoneyama, T. Hashimoto, K. Arai, Polym. Prepr. Jpn. 43 (1994) 177.

[3] T. Kartvelishvili, G. Tsitlanadze, L. Edilashvili, N. Japaridze, R. Katsarava, Amino acid based bioanalogous polymers. Novel regular poly(ester urethane)s and poly(ester urea)s based on bis(L-phenylalanine) $\alpha$, $\omega$-alkylene diesters, Macromol. Chem. Phys. 198 (1997) (1921-1932). 
[4] Z.D. Gomurashvili, R. Katsarava, D. Tugushi, Poly(Ester Urea) Polymers and Methods of use, 2007. (WO 2007050415).

[5] R. Katsarava, V. Beridze, N. Arabuli, D. Kharadze, C.C. Chu, C.Y. Won, Amino acid based bioanalogois polymers. Synthesis and study of regular poly(ester amide)s based on bis $(\alpha$-amino acid) $\alpha, \omega$-alkylene diesters and aliphatic dicarboxylic acids, J. Polym. Sci. A Polym. Chem. 37 (1999) 391-407.

[6] D.H. Reneker, I. Chun, Nanometre diameter fibres of polymer, produced by electrospinning, Nanotechnology 7 (1996) 216-223.

[7] A. Frenot, I.S. Chronakis, Polymer nanofibers assembled by electrospinning, Curr. Opin. Colloid Interface Sci. 8 (2003) 64-75.

[8] Y. Dzenis, Spinning continuous fibers for nanotechnology, Science 304 (2004) 1917-1919.

[9] K. Jayaraman, M. Kotaki, Y. Zhang, X. Mo, S. Ramakrishna, Recent advances in polymer nanofibers, J. Nanosci. Nanotechnol. 4 (2004) 52-65.

[10] S.R. Dhakate, B. Singla, M. Uppal, R.B. Mathur, Effect of processing parameters on morphology and thermal properties of polycarbonate nanofibers, Adv. Mater. Lett. 1 (2010) 200-204.

[11] S. Sharma, Ferroelectric nanofibers: principle, processing and applications, Adv. Mater. Lett. 4 (2013) 522-533.

[12] Y. Wu, M. Gao, X. Li, Y. Liu, H. Pan, Preparation of mesohollow and microporous carbon nanofiber and its application in cathode material for lithium-sulfur batteries, J. Alloys Compd. 608 (2014) 220-228.

[13] H. Kim, L. Che, Y. Ha, W. Ryu, Mechanically-reinforced electrospun composite silk fibroin nanofibers containing hydroxyapatite nanoparticles, Mater. Sci. Eng. C 40 (2014) 324-335.

[14] Q. Guo, D. Liu, X. Zhang, L. Li, H. Hou, O. Niwa, T. You, Pd-Ni alloy nanoparticle/carbon nanofiber composites: preparation, structure, and superior electrocatalytic properties for sugar analysis, Anal. Chem. 86 (2014) 5898-5905.

[15] W.Q. Li, S.Y. Ma, J. Luo, Y.Z. Mao, L. Cheng, D.J. Gengzang. X.L. Xu, S.H. Ya, Synthesis of hollow $\mathrm{SnO}_{2}$ nanobelts and their application in acetone sensor, Mater. Lett. 132 (2014) 338-341.

[16] S. Shahverdi, M. Hajimiri, M.A. Esfandiari, B. Larijani, F. Atyabi, A. Rajabiani, A.R. Dehpour, A.A. Gharehaghaji, R. Dinarvand, Fabrication and structure analysis of poly(lactide-co-glycolic acid)/silk fibroin hybrid scaffold for wound dressing applications, Int. J. Pharm. 473 (2014) 345-355.

[17] M.J.A. Shirazi, S. Bazgir, M.M.A. Shirazi, Edible oil mill effluent; a low-cost source for economizing biodiesel production: electrospun nanofibrous coalescing filtration approach, Biofuel Res. J. 1 (2014) 39-42.

[18] M.M.A. Shirazi, A. Kargari, S. Bazgir, M. Tabatabaei, M.J.A. Shirazi, M.S. Abdullah, T. Matsuura, A.F. Ismail, Characterization of electrospun polystyrene membrane for treatment of biodiesel's water-washing effluent using atomic force microscopy, Desalination 329 (2013) 1-8.

[19] M.J.A. Shirazi, S. Bazgir, M.M.A. Shirazi, S. Ramakrishna, Coalescing filtration of oily wastewaters: characterization and application of thermal treated, electrospun polystyrene filters, Desalin. Water Treat. 51 (2013) 5974-5986.

[20] E. Mirtalebi, M.M.A. Shirazi, A. Kargari, M. Tabatabaei, S. Ramakrishna, Assessment of atomic force and scanning electron microscopes for characterization of commercial and electrospun nylon membranes for coke removal from wastewater, Desalin. Water Treat. (2014) 1-10.

[21] R. Dersch, M. Steinhart, U. Boudriot, A. Greiner, J.H. Wendorff, Nanoprocessing of polymers: applications in medicine, sensors, catalysis, photonics, Polym. Adv. Technol. 16 (2005) 276-282.

[22] Y. You, B.M. Min, S.J. Lee, T.S. Lee, W.H. Park, In vitro degradation behavior of electrospun polyglycolide, polylactide, and poly(lactide-co-glycolide), J. Appl. Polym. Sci. 95 (2005) 193-200.

[23] S. Cao, B. Hu, H. Liu, Fabrication of nano-porous structured polylactide (PLLA) fibers through electrospinning, Acta Polym. Sin. 20 (2010) 1193-1198.

[24] V. Thomas, M.V. Jose, S. Chowdhury, J.F. Sullivan, D.R. Dean, Y.K. Vohra, Mechanomorphological studies of aligned nanofibrous scaffolds of polycaprolactone fabricated by electrospinning, J. Biomater. Sci. Polym. Ed. 17 (2006) 969-984.

[25] S.A. Sell, M.J. McClure, K. Garg, P.S. Wolfe, G.L. Bowlin, Electrospinning of collagen/ biopolymers for regenerative medicine and cardiovascular tissue engineering, Adv. Drug Deliv. Rev. 61 (2009) 1007-1019.

[26] Z. Chen, X. Mo, F. Qing, Electrospinning of collagen-chitosan complex, Mater. Lett. 61 (2007) 3490-3494.

[27] H. Homayoni, S.A.H. Ravandi, M. Valizadeh, Electrospinning of chitosan nanofibers: processing optimization, Carbohydr. Polym. 77 (2009) 656-661 (Review).

[28] Y. Gao, Y.B. Truong, Y. Zhu, I.L. Kyratzis, Electrospun antibacterial nanofibers: production, activity, and in vivo applications, J. Appl. Polym. Sci. 131 (2014) 40797-40810.

[29] L.J. del Valle, R. Camps, A. Díaz, L. Franco, A. Rodríguez-Galán, J. Puiggalí, Electrospinning of polylactide and polycaprolactone mixtures for preparation of materials with tunable drug release properties, J. Polym. Res. 18 (2011) 1903-1917.

[30] F. Kayaci, O.C.O. Umu, T. Tekinay, T. Uyar, Antibacterial electrospun poly(lactic acid) (PLA) nanofibrous webs incorporating triclosan/cyclodextrin inclusion complexes, J. Agric. Food Chem. 61 (2013) 3901-3908.
[31] L. Chen, L. Bromberg, T.A. Hatton, G.C. Rutledge, Electrospun cellulose acetate fibers containing chlorhexidine as a bactericide, Polymer 49 (2008) 1266-1275.

[32] E. Gliscinska, B. Gutarowska, B. Brycki, I.a Krucinska, Electrospun polyacrylonitrile nanofibers modified by quaternary ammonium salts, J. Appl. Polym. Sci. 128 (2013) 767-775

[33] X. Liu, T. Lin, Y. Gao, Z. Xu, C. Huang, G. Yao, L. Jiang, Y. Tang, X. Wang, Antimicrobial electrospun nanofibers of cellulose acetate and polyester urethane composite for wound dressing. J. Biomed. Mater. Res. B 100B (2012) (2012) 1556-1565.

[34] Y. Mei, C. Yao, K. Fan, X. Li, Surface modification of polyacrylonitrile nanofibrous membranes with superior antibacterial and easy-cleaning properties through hydrophilic flexible spacers, J. Membr. Sci. 417 (2012) 20-27.

[35] X. Ren, H.B. Kocer, S.D. Worley, R.M. Broughton, T.S. Huang, Biocidal nanofibers via electrospinning, J. Appl. Polym. Sci. 127 (2013) 3192-3197.

[36] M. Spasova, N. Manolova, D. Paneva, I. Rashkov, Preparation of chitosan-containing nanofibres by electrospinning of chitosan/poly(ethylene oxide) blend solutions, EPolymers 4 (2004) 1-12.

[37] T. Heunis, O. Bshena, B. Klumperman, L. Dicks, Release of bacteriocins from nanofibers prepared with combinations of poly(D, L-lactide) (PDLLA) and poly(ethylene oxide) (PEO), Int. J. Mol. Sci. 12 (2011) 2158.

[38] L.J. Del Valle, M. Roa, A. Díaz, M.T. Casas, J. Puiggalí, A. Rodríguez-Galán, Electrospun nanofibers of a degradable poly(ester amide). Scaffolds loaded with antimicrobial agents, J. Polym. Res. 19 (2012) 9792-9805.

[39] L.J. Del Valle, A. Díaz, M. Royo, A. Rodríguez-Galán, J. Puiggalí, Biodegradable polyesters reinforced with triclosan loaded polylactide micro/nanofibers: properties, release and biocompatibility, Express Polym. Lett. 6 (2012) 266-282.

[40] E. Llorens, L.J. Del Valle, R. Ferrán, A. Rodríguez-Galán, J. Puiggalí, Scaffolds with tuneable hydrophilicity from electrospun microfibers of polylactide and poly(ethylene glycol) mixtures: morphology, drug release behavior, and biocompatibility, J Polym. Res. 21 (2014) 360-375.

[41] J.G. Fernandes, D.M. Correia, G. Botelho, J. Padrão, F. Dourado, C. Ribeiro, S. LancerosMéndez, V. Sencadas, PHB-PEO electrospun fiber membranes containing chlorhexidine for drug delivery applications, Polym. Test. 34 (2014) 64-71.

[42] R. Ben-Knaz, R. Pedahzur, D. Avenir, A concept in bactericidal materials: the entrapment of chlorhexidine within silver, Adv. Funct. Mater. 20 (2010) 2324-2329.

[43] J.B.D. Green, T. Fulghum, M.A. Nordhaus, Immobilized antimicrobial agents: a critical perspective, in: Méndez-Vilas (Ed.), Science Against Microbial Pathogens: Communicating Current Research And Technological Advances, Formatex Microbiology Books Series, Badajoz, España, 2011, pp. 84-98.

[44] K. Vasilev, J. Cook, H. Griesser, Antibacterial surfaces for biomedical devices, Expert Rev. Med. Devices 6 (2009) 553-567.

[45] M. Charnley, M. Textor, C. Acikgoz, Designed polymer structures with antifoulingantimicrobial properties, React. Funct. Polym. 71 (2011) 329-334.

[46] A. Milstone, C. Passaretti, T. Perl, Chlorhexidine: expanding the armamentarium for infection control and prevention, Clin. Infect. Dis. 46 (2008) 274-281.

[47] K. Lim, P. Kam, Chlorhexidine - pharmacology and clinical applications, Anaesth. Intensive Care 36 (2008) 502-512.

[48] G. De Paula, G. Netto, L. Mattoso, Physical and chemical characterization of poly(hexamethylene biguanide) hydrochloride, Polymers 3 (2011) 928-941.

[49] B. Roth, F.H.H. Brill, Polihexanide for wound treatment-how it began, Skin Pharmacol. Physiol. 23 (2010) 4-6.

[50] M.J. Allen, G.F. White, A.P. Morby, The response of Escherichia coli to exposure to the biocide polyhexamethylene biguanide, Microbiology 152 (2006) 989-1000.

[51] P. Gilbert, D. Pemberton, D.E. Wilkinson, Synergism within polyhexamethylene biguanide biocide formulations, J. Appl. Bacteriol. 69 (1990) 593-598.

[52] E. Llorens, L.J. del Valle, A. Díaz, M.T. Casas, J. Puiggalí, Polylactide nanofibers loaded with vitamin $\mathrm{B}_{6}$ and polyphenols as bioactive platform for tissue engineering, Macromol. Res. 21 (2013) 775-787.

[53] S.V. Fridrikh, J.H. Yu, M.P. Brenner, G.C. Rutledge, Controlling the fiber diameter during electrospinning, Phys. Rev. Lett. 90 (2003) 144502-144504.

[54] M.G. McKee, C.L. Elkins, T.E. Long, Influence of self-complementary hydrogen bonding on solution rheology/electrospinning relationships, Polymer 45 (2004) 8705-8715.

[55] C.J. Luo, M. Nangrejo, M. Edirisinghe, A novel method of selecting solvents for polymer electrospinning, Polymer 51 (2010) 1654-1662.

[56] R. Wenzel, Resistance of solid surfaces to wetting by water, Ind. Eng. Chem. 28 (1936) 988-994.

[57] A.B.D. Cassie, S. Baxter, Wettability of porous surfaces, Trans. Faraday Soc. 40 (1944) 546-551.

[58] H. Jia, Enzyme-carrying electrospun nanofibers, in: N.J. Clifton (Ed.), Methods in Molecular Biology, 743, 2011, pp. 205-212.

[59] G. Tsitlanadze, M. Machaidze, T. Kviria, N. Djavakhishvili, C.C. Chu, R. Katsarava, Biodegradation of amino-acid-based poly(ester amide)s: in vitro weight loss and preliminary in vivo studies, J. Biomater. Sci. Polym. Ed. 15 (2004) 1-24.

[60] H. Liu, K. Leonas, Y. Zhao, Antimicrobial properties and release profile of ampicillin from electrospun poly( $\varepsilon$-caprolactone) nanofiber yarns, J. Eng. Fiber Fabr. 5 (2010) 10-19. 